\title{
A Comprehensive Negative Regulatory Program Controlled by Brn3b to Ensure Ganglion Cell Specification from Multipotential Retinal Precursors
}

\author{
Feng Qiu, ${ }^{1 \star}$ Haisong Jiang, ${ }^{1,2 *}$ and Mengqing Xiang ${ }^{1,2}$ \\ ${ }^{1}$ Center for Advanced Biotechnology and Medicine and Department of Pediatrics and ${ }^{2}$ Graduate Program in Molecular Genetics and Microbiology, Robert \\ Wood Johnson Medical School, University of Medicine and Dentistry of New Jersey, Piscataway, New Jersey 08854
}

\begin{abstract}
The retinal ganglion cells (RGCs) are the sole output neurons in the retina that form the optic nerve and convey light signals detected by photoreceptors to the higher visual system. Their degeneration and damage caused by glaucoma and injury can lead to blindness. During retinogenesis, RGCs are specified from a population of multipotential precursors capable of generating RGC, amacrine, horizontal, and cone cells. How the RGC fate is selected from these multiple neuron fates is unknown at present. Here we show that the previously unsuspected POU domain transcription factor Brn3b (brain-specific homeobox/POU domain protein $3 \mathrm{~b}$ ) plays such a critical role. Loss of $B r n 3 b$ function in mice leads to misspecification of early RGC precursors as late-born RGC, amacrine, and horizontal cells, whereas misexpressed Brn3b suppresses non-RGC cell fates but promotes the RGC fate. Microarray profiling and other molecular analyses reveal that, in RGC precursors, Brn3b normally represses the expression of a network of retinogenic factor genes involved in fate commitment and differentiation of late-born RGC, amacrine, horizontal, and cone cells. Our data suggest that Brn3b specifies the RGC fate from multipotential precursors not only by promoting RGC differentiation but also by suppressing non-RGC differentiation programs as a safeguard mechanism.
\end{abstract}

Key words: Brn3b; POU domain transcription factor; retina; retinogenesis; ganglion cell; amacrine cell; horizontal cell

\section{Introduction}

During vertebrate retinogenesis, the multipotent progenitor cells give rise to six classes of neurons that include the rod, cone, bipolar, horizontal, amacrine, and retinal ganglion cells (RGCs) and one type of glia, the Müller cells. The commitment and differentiation of these seven classes of cells require the coordinated action of various intrinsic and extrinsic factors (Harris, 1997; Dyer and Cepko, 2001; Livesey and Cepko, 2001). The RGCs are the sole output neurons in the retina that convey light signals to the brain via the optic nerve and tract. RGC degeneration and optic nerve damage caused by glaucoma and injury can lead to blindness (Harvey et al., 2006; Gupta and Yucel, 2007). Their development and possible regeneration have thus long become a topic of extensive investigation and the intrinsic and extrinsic factors associated with their development have begun to be elucidated.

In the mouse retina, Gdf11 (growth differentiation factor 11)

Received Jan. 4, 2008; revised Feb. 13, 2008; accepted Feb. 15, 2008.

This work was supported by the National Institutes of Health Grants EY012020 and EY015777 (M.X.). We thank Dr. Lin Gan (University of Rochester, Rochester, NY) for providing the Brn3b lacZ knock-in mice and Bhlhb5 plasmid, Dr. Qiufu Ma (Harvard Medical School, Boston, MA) for the Viaat and VGlut2 plasmids, Dr. Shiming Chen (Washington University, St. Louis, M0) for the (rx plasmid, Dr. Huijun Luo for the Notch1, Hes1, Hes5, and Otx2 plasmids, and Dr. Xuesong Ouyang and Zeqian Mo for technical assistance in microarray analysis and microinjection, respectively.

${ }^{*}$ F.Q. and H.J. contributed equally to this work.

Correspondence should be addressed to Dr. Mengqing Xiang, Center for Advanced Biotechnology and Medicine, 679 Hoes Lane, Piscataway, NJ 08854. E-mail: xiang@cabm.rutgers.edu.

DOI:10.1523/JNEUROSCI.0043-08.2008

Copyright (C) 2008 Society for Neuroscience $\quad 0270-6474 / 08 / 283392-12 \$ 15.00 / 0$ and follistatin are found to control progenitor competence by shortening or elongating the duration of expression of the mouse atonal homolog Ath5 (Math5) basic helix-loop-helix (bHLH) transcription factor (TF) gene (Kim et al., 2005). Inactivating Ath5 in the mouse and zebrafish nearly eliminates RGCs but meanwhile causes an overproduction of other cell types such as amacrine and cone cells (Brown et al., 2001; Kay et al., 2001; Wang et al., 2001; Le et al., 2006). In contrast, Ath5 overexpression leads to increased RGCs (Kanekar et al., 1997; Liu et al., 2001; Ma et al., 2004). By lineage tracing, Math5-expressing precursors are found to produce as progeny RGC, amacrine, horizontal, and photoreceptor cells (Yang et al., 2003), indicating that Math5 is required only for competence acquisition of but not for fate commitment to RGCs.

The regulation of $\mathrm{Brn} 3 \mathrm{~b}$ (brain-specific homeobox/POU domain protein $3 \mathrm{~b}$ ) expression by Math5 has been identified as the major molecular pathway underlying RGC differentiation (Wang et al., 2001; Yang et al., 2003; Mu et al., 2005). Brn3b is a POU domain TF expressed by migrating RGC precursors as well as differentiating and mature RGCs (Xiang et al., 1993; Gan et al., 1996). Ablating Brn3b results in a wide range of defects in RGC differentiation and survival (Erkman et al., 1996, 2000; Gan et al., 1996, 1999; Xiang, 1998; Wang et al., 2000), whereas misexpressed Brn3b facilitates RGC differentiation from chick retinal progenitors (Liu et al., 2000b). Part of the Brn3b function has been shown to be mediated by the T-box TF Eomes (eomesodermin homolog) (Mao et al., 2008). Brn3b appears to be required 
for development of early-born RGCs, because the differentiation and survival of late-born RGCs critically depend on the Dlx1 (distal-less homeobox 1) and Dlx2 homeodomain TFs (de Melo et al., 2005).

Despite its essential role in RGC development, it is essentially unknown at present how Brn3b promotes RGC differentiation from the multipotential RGC precursors. It has been suggested that Brn3b may act only as a "differentiation" gene but not as a "specifier" gene for RGCs (Gan et al., 1999; Mu and Klein, 2004). This hypothesis is based primarily on the observation that, in

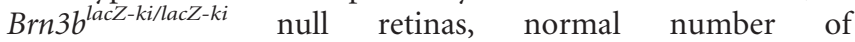
$\beta$-galactosidase-positive $\left(\beta\right.$-gal $\left.{ }^{+}\right)$cells is initially produced that migrate into inner retinal layers (Gan et al., 1999). However, a role for Brn3b in RGC fate commitment cannot be ruled out because there has been no thorough molecular analysis to confirm all the $\beta$-gal ${ }^{+}$cells as RGCs in Brn3b lacZ-ki/lacZ-ki retinas. In this work, we demonstrated such a role for Brn3b.

\section{Materials and Methods}

Animals. The Brn3b knock-out and knock-in mice were generated previously (Gan et al., 1996, 1999) and maintained in our laboratory. The stage of mouse embryos was determined by taking the morning when the copulation plug was seen as embryonic day 0.5 (E0.5). All genotypes described were confirmed by PCR. For clarity, the genotypes of the original knock-out animals were indicated by $\mathrm{Brn}_{3} \mathrm{~b}^{+/-}$and $\mathrm{Brn} 3 \mathrm{~b}^{-/-}$(Gan et al., 1996) and those of the lacZ knock-in animals by Brn3b ${ }^{+/ l a c Z}$ and Brn3b lacZ/lacZ (Gan et al., 1999) in this work.

Microarray profiling and quantitative reverse transcription-PCR analyses. E14.5 retinas were dissected from $\mathrm{Brn} 3 \mathrm{~b}^{+/-}$and $\mathrm{Brn} 3 \mathrm{~b}^{-/-}$mice and stored in the RNAlater solution (Ambion, Austin, TX). Total RNA was isolated as described previously ( $\mathrm{Li}$ et al., 2004a). Total RNA $(1 \mu \mathrm{g})$ of each sample from different genotypes was amplified and biotin-labeled using the MessageAmp II aRNA kit (Ambion). Microarray analysis was performed according to the technical manual of the vendor using the GeneChip mouse expression arrays (430A; Affymetrix, Santa Clara, CA). Briefly, $15 \mu \mathrm{g}$ of biotin-labeled cRNA was hybridized to each microarray chip, which was then scanned using the GeneChip scanner (Affymetrix). Signal intensity and detection (absence/presence) calls were determined using the Microarray Suite software (Affymetrix). The absolute intensity values of each chip were scaled to the all-probe-set intensity by 500 target signals. Six-chip comparisons were performed using samples from three each $\mathrm{Brn}_{3} b^{+/-}$and $\mathrm{Brn} 3 b^{-/-}$mice. Upregulated and downregulated genes with $a \geq 1.7$-fold change and statistical significance $(p<0.05)$ were identified by the DNA-Chip Analyzer (dChip) software package (Li and Wong, 2003).

For real-time quantitative reverse transcription ( $\mathrm{qRT}$ )-PCR, RNA samples from E14.5 $\mathrm{Brn} 3 \mathrm{~b}^{+/+}, \mathrm{Brn} 3 \mathrm{~b}^{+/-}$, and $\mathrm{Brn} 3 \mathrm{~b}^{-/-}$retinas were prepared, and one-step qRT-PCR was performed using the ABI 7900HT sequence detection system as described previously (Li et al., 2004a; Fujitani et al., 2006). Relative quantities were calculated by the comparative cycle threshold method $\left(\Delta \Delta \mathrm{C}_{\mathrm{T}}\right.$ method) (Pfaffl, 2001). Sequencespecific primers were designed using the MacVector software (Accelrys, San Diego, CA) and listed in supplemental Table S3 (available at www. jneurosci.org as supplemental material). All data were tested for significance using two-sample Student's $t$ test with unequal variances.

In situ hybridization and birthdating. RNA in situ hybridization was performed as described using digoxigenin-labeled antisense riboprobes (Liu et al., 2001; Mo et al., 2004). The following probes were used: Viaat (vesicular inhibitory amino acid transporter), VGlut2 (vesicular glutamate transporter 2), Crx (cone-rod homeobox), and Bhlhb5 were described previously (Chen et al., 1997; Cheng et al., 2004; Feng et al., 2006); Nr4a2 (nuclear receptor subfamily 4, group A, member 2) was a PCR-amplified partial coding sequence containing 774-1370 bp of the open reading frame (ORF); Zfhx4 (zinc finger homeodomain 4) was 10,359-10,460 bp of the ORF; Dlx1 was $1427-2024$ bp of the ORF; Dlx2 was 1196-1790 bp of the ORF; Thrb2 (thyroid hormone receptor beta 2) was 397-895 bp of the ORF; Otx2 (orthodenticle-related protein 2) was
678-1227 bp of the ORF; Hes1 (hairy and enhancer of split 1) was 309684 bp of the ORF; Hes 5 was $444-1113$ bp of the ORF; Notch1 was 2223-2806 bp of the ORF; Ngn2 (neurogenin 2) was the full-length coding sequence; and Proxl (prospero-related homeobox 1) was a PCRamplified product from the fifth exon.

For birthdating analysis, newborn retinal cells were pulse labeled by bromodeoxyuridine (BrdU) at E12.5, E14.5, and E16.5 as described previously (Xiang, 1998). The labeled retinas were then harvested at postnatal day 4 (P4) and double immunostained with antibodies against BrdU and $\beta$-gal.

Virus preparation and infection. To construct the Brn3b-green fluorescent protein (GFP) plasmid, a full-length human Brn3b cDNA was bluntly ligated into the control-GFP vector (Mo et al., 2004). Virus preparation and infection were performed as described previously (Mo et al., 2004). P0 retinas were infected in vivo and were harvested and analyzed at P21. Explanted retinas were infected at E13.5 and harvested for analysis after 4.5 or $12.5 \mathrm{~d}$ in culture.

Immunofluorescence and quantification. The preparation of retinal sections, immunofluorescent labeling of retinal sections, and quantification of immunoreactive cells were performed as described previously (Mo et al., 2004; Li et al., 2005). The following primary antibodies were used: anti-tyrosine hydroxylase ( $\mathrm{TH}$ ) (sheep polyclonal; Millipore Bioscience Research Reagents, Temecula, CA); anti-syntaxin (mouse monoclonal; Sigma St. Louis, MO); anti- $\beta$-gal (rabbit polyclonal; Cappel Laboratories, Durham, NC); anti-GABA (rabbit polyclonal; Sigma); anti-GABA transporter 1 (GAT-1) (rabbit polyclonal; Millipore Bioscience Research Reagents); anti-calbindin-D28K (rabbit polyclonal; Swant, Bellizona, Switzerland); anti-Neurod1 (neurogenic differentiation 1) (mouse monoclonal and goat polyclonal; Santa Cruz Biotechnology, Santa Cruz, CA); anti-Lim1/2 (mouse monoclonal; Developmental Studies Hybridoma Bank, University of Iowa, Iowa City, IA); anti-Brn3a (mouse monoclonal; Millipore Bioscience Research Reagents); anti-Brn3b (goat polyclonal; Santa Cruz Biotechnology); anti-Brn3c (rabbit polyclonal) (Xiang et al., 1995); anti-retinoid X receptor $\gamma(\mathrm{RXR} \gamma)$ (rabbit polyclonal; Santa Cruz Biotechnology); anti-Pax6 (paired box gene 6) (rabbit polyclonal; Millipore Bioscience Research Reagents); anti-GFP [rabbit polyclonal (MBL International, Woburn, MA); goat polyclonal (Abcam, Cambridge, MA)]; anti-recoverin (rabbit polyclonal) (Dizhoor et al., 1991); anti-glycine transporter 1 (GLYT1) (goat polyclonal; Millipore Bioscience Research Reagents); anti-Chx10 (ceh-10 homeodomain containing homolog) (sheep polyclonal; Exalpha Biologicals, Maynard, $\mathrm{MA}$ ); and anti-protein kinase $\mathrm{C} \alpha(\mathrm{PKC} \alpha)$ (mouse monoclonal; GE Healthcare, Little Chalfont, UK). Alexa Fluor 488/594-conjugated donkey IgGs (anti-different species) were used as secondary antibodies (Invitrogen, Carlsbad, CA) and 4',6'-diamidino-2-phenylindole (DAPI) (Vector Laboratories, Burlingame, CA) for nuclear counterstaining.

\section{Results}

\section{Brn3b negatively regulates a wide network of retinal developmental genes}

To identify candidate downstream genes regulated by Brn3b during retinal development, we performed microarray analysis using the Mouse Expression 430A arrays (Affymetrix), each of which covers $>14,000$ characterized mouse genes. To minimize experimental and array variations, array hybridization was performed in triplicates using probes derived from E14.5 retinas of $\mathrm{Brn} \mathrm{b}^{+/-}$ and $\mathrm{Brn}_{3} \mathrm{~b}^{-1-}$ mice (Gan et al., 1996). The obtained data were analyzed using the Affymetrix Microarray Suite software to obtain absence/presence calls and the dChip software package (Li and Wong, 2003) to calculate fold changes of transcripts between the control and mutant. Aside from several upregulated crystallin genes that were presumed to come from lens contamination (Blackshaw et al., 2004), we found that 190 transcripts displayed a decrease or increase of 1.7-fold or higher in their expression levels in Brn3b null mutant retinas. One hundred thirty of them are downregulated and 60 are upregulated (Fig. 1) (supplemental Table S1, available at www.jneurosci.org as supplemental mate- 

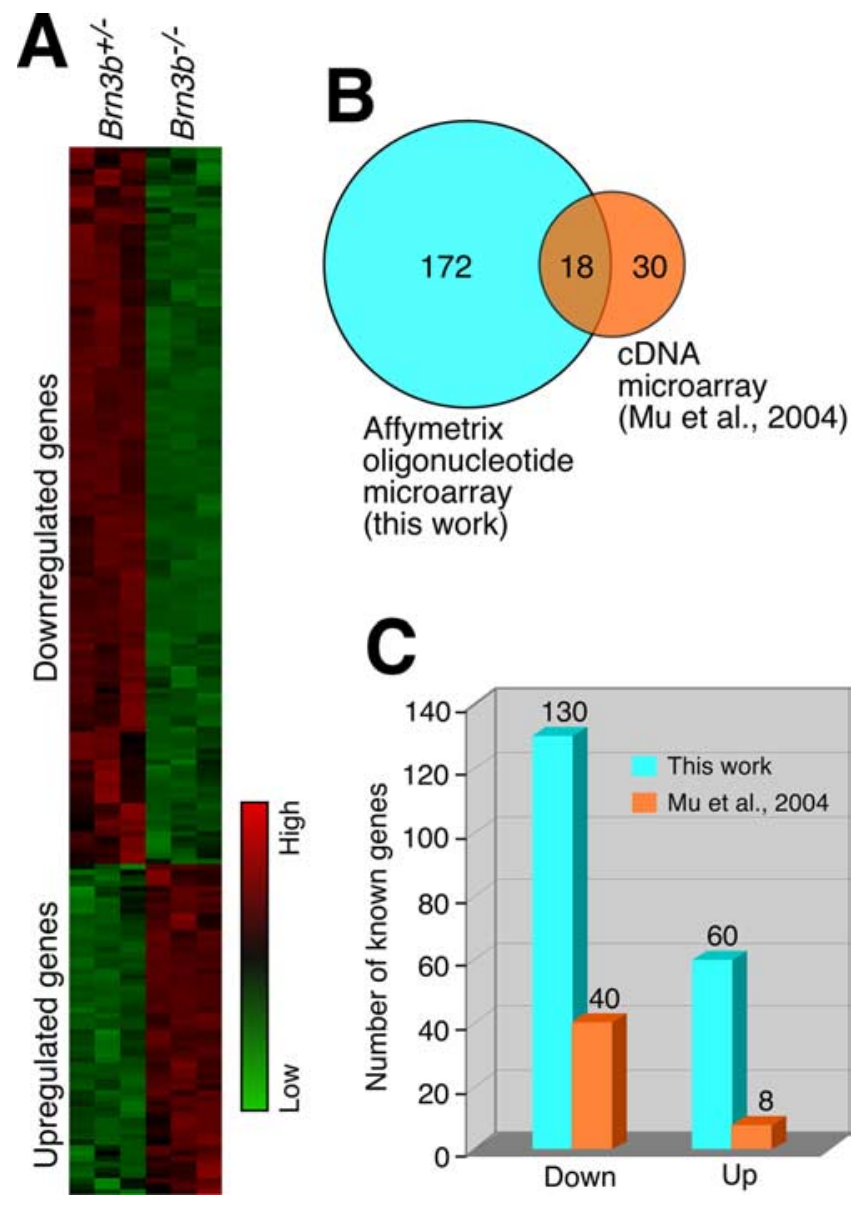

transporter genes (supplemental Table S2, available at www. jneurosci.org as supplemental material).

Our dataset of differentially expressed genes features a large number of upregulated genes in Brn3b null retinas that were not appreciated previously (Fig. $1 C$ ). Among these are the $D l x 1$ and $D l \times 2$ homeobox genes that are required for differentiation and survival of late-born RGCs (de Melo et al., 2005) and the Bhlhb5 bHLH gene that is involved in amacrine and bipolar cell differentiation (Feng et al., 2006). Some of the most upregulated genes are TH, Slc32a1 (VIAAT), Slc6a1 (GAT-1), Slc18a3 (vesicular acetylcholine transporter), and Gad1 [glutamic acid decarboxylase 1 (GAD67)], which are normally expressed by amacrine and/or horizontal cells (supplemental Table S1, available at www. jneurosci.org as supplemental material). Therefore, our gene expression profiling study has revealed that Brn3b may have an important, previously unrecognized role. That is, it may suppress the differentiation of other retinal cell types besides promoting RGC differentiation.

To understand how Brn3b may exert this negative regulatory effect, we examined in microarrays the expression profiles of all known transcription factor genes involved in retinal specification and differentiation. In this analysis, genes with significant signal differences were included, and we made no threshold cut and ignored the arbitrary presence/absence call. An interesting pattern emerged from this analysis. Except for a few downregulated factors that are expressed and/or involved in RGC development, all other analyzed transcription factor genes are upregulated in $B r n 3 b$ null retinas (Fig. $2 A$ ). Consistent with the microarray data, real-time qRT-PCR analysis confirmed a significant upregulation in mRNA expression of Math3, Neurod1, Ptfla (pancreas specific transcription factor, 1a), Crx, Math5, and Wt1 (Wilms tumor 1) in the mutant retina (Fig. $2 B$ ). The upregulation of $D l \times 1$ and $D l \times 2$ suggests that Brn3b may normally suppress the differentiation of late-born RGCs (de Melo et al., 2005). Math3, Neurod1, Ptf1a, and Bhlhb5, which are required for amacrine cell specification (Inoue et al., 2002; Feng et al., 2006; Fujitani et al., 2006), are all upregulated in the mutant, consistent with the upregulation of several mature amacrine marker genes described above. Ptfla, Prox1, Ngn2, and Lim1 are involved in horizontal cell development (Dyer et al., 2003; Akagi et al., 2004; Fujitani et al., 2006; Poche et al., 2007), and their upregulation may implicate a repression of horizontal cell development by Brn3b. The upregulation of Otx2, Crx , Thrb2, and Prdm1 (PR domain containing 1, with ZNF domain)/Blimp1 (B-lymphocyte-induced maturation protein 1), genes involved in photoreceptor cell development (Furukawa et al., 1997, 1999; Ng et al., 2001; Nishida et al., 2003; Wilm and Solnica-Krezel, 2005), implies that Brn3b may have a negative impact on photoreceptor development as well. Conversely, Math 5 and Wt1 are transiently expressed by retinal progenitors/precursors and appear to confer them with an RGC competence (Wagner et al., 2002; Yang et al., 2003). Their upregulation in Brn $3 b$ null retinas suggests that Brn3b may repress their expression by a feedback mechanism when a precursor becomes determined to differentiate as an RGC.

(supplemental Table S2, available at www.jneurosci.org as supplemental material), suggesting that Brn3b sits on top of a regulatory gene network. Consistent with the function of Brn3b in RGC development, genes involved in morphogenesis, nervous system development, neuronal cell projection, synaptic vesicle, and neurofilament are all enriched (supplemental Table S2, available at www.jneurosci.org as supplemental material). For upregulated genes, those involved in transcription, chromatin assembly or disassembly, and cell differentiation are enriched. Notably, prominent among the enriched genes are those that encode neurotransmitter transporters including two GABA

\section{Abnormal generation of amacrine cells in $B r n 3 b$ null retinas} Our microarray analysis identified $\mathrm{TH}$ as the most upregulated gene in E14.5 Brn3b null retinas (supplemental Table S1, available at www.jneurosci.org as supplemental material). We verified this result by qRT-PCR and immunostaining assays. In E14.5 $B r n 3 b^{-/-}$retinas, qRT-PCR revealed an $\sim 54$-fold increase in the Th mRNA level compared with that of $B r n 3 b^{+/+}$retinas

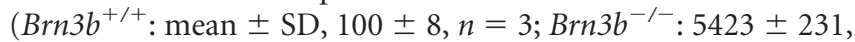



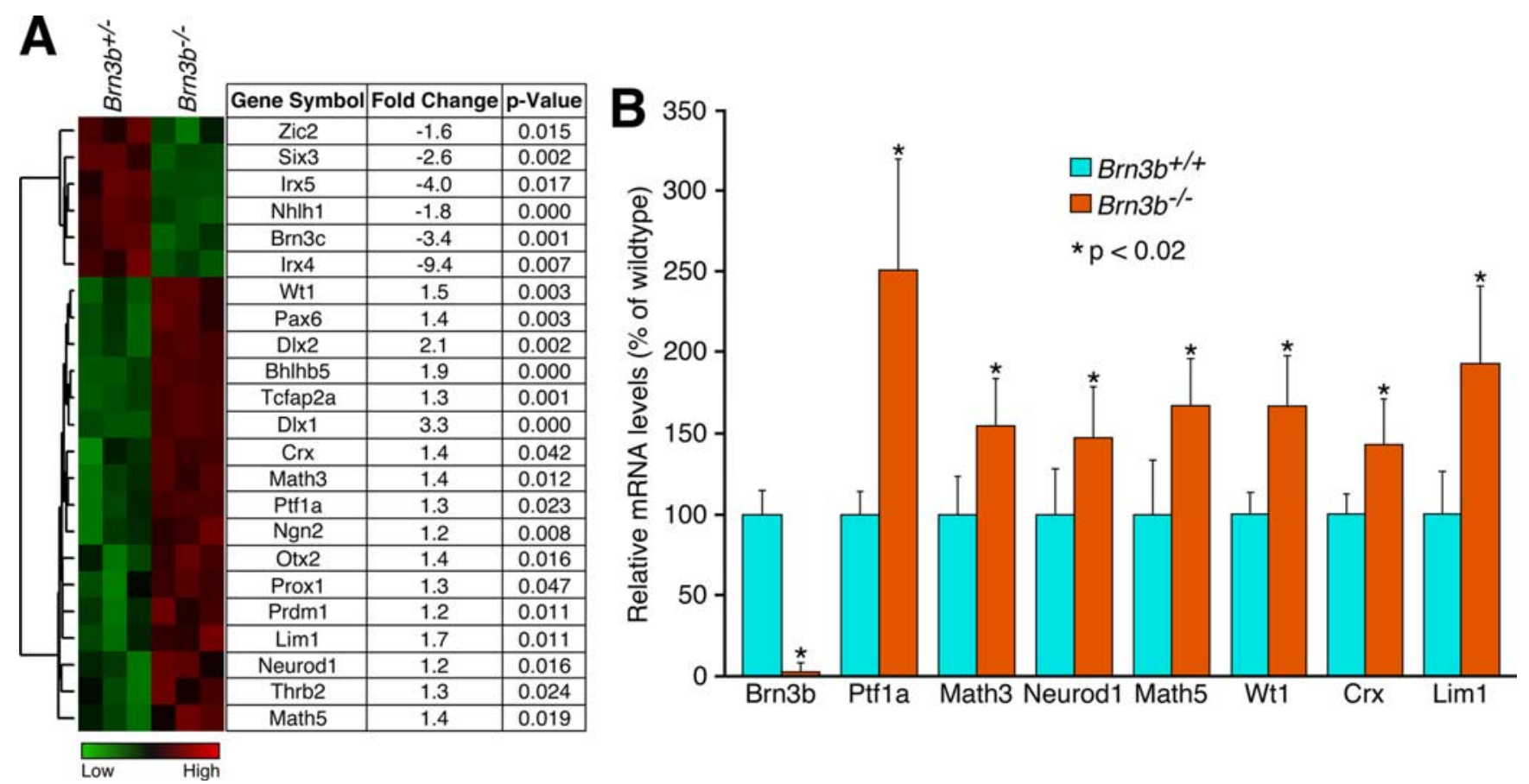

Figure 2. Known retinogenic transcription factor genes whose expression is altered in Brn3b null retinas at E14.5. A, Clustering analysis of known transcription factor genes whose expression shows a statistically significant change in the mutant retina. $\boldsymbol{B}$, Relative mRNA levels of the indicated transcription factor genes determined by qRT-PCR analysis. Each histogram represents the mean \pm SD for six duplicated samples.

$n=3)$. At E14.5-E15.5, weak TH immunoreactivity was found only in few cells within the inner neuroblastic layer (INBL) of $\mathrm{Brn} 3 \mathrm{~b}^{+/+}$and $\mathrm{Brn} 3 \mathrm{~b}^{+/-}$retinas (Fig. $3 A, C$ ), whereas in $B r n 3 b$ null retinas, there was a dramatic increase in the number of TH-immunoreactive cells in the INBL and outer neuroblastic layer (ONBL) (approximate fourfold increase compared with $\mathrm{Brn} 3 \mathrm{~b}^{+/-}$retinas; $\mathrm{Brn} 3 \mathrm{~b}^{+/-}$: mean $\pm \mathrm{SD}$, $28.0 \pm 9.8$ cells/optical field, $n=5$ $B r n 3 b^{-/-}: 100.4 \pm 14.0$ cells/optical field, $n=5$ ) (Fig. $3 B, D$ ). In addition, the nerve fiber layer was strongly labeled in null retinas (Fig. $3 B, D$ ), indicating that a large population of cells within the mutant INBL aberrantly express $\mathrm{TH}$, which is normally expressed only by dopaminergic amacrine cells. In the ensuing stages, the population of TH-immunoreactive cells in null retinas decreased by E16.5 and became nearly completely lost by P0 (Fig. $3 E-H$ ), consistent with increased apoptotic cell death observed previously in the mutant INBL at E15.5 to P0 (Xiang, 1998; Gan et al., 1999). Double immunolabeling revealed that THimmunoreactive cells could be colabeled for amacrine cell markers syntaxin and calbindin but not for RGC markers Brn3a or Brn3c (Figs. 3I,J, 4G,H) (see Fig. $6 E, F, I, J)$, suggesting that these cells develop as amacrine cells.

To ask whether the supernumerary $\mathrm{TH}^{+}$cells were derived cell autonomously
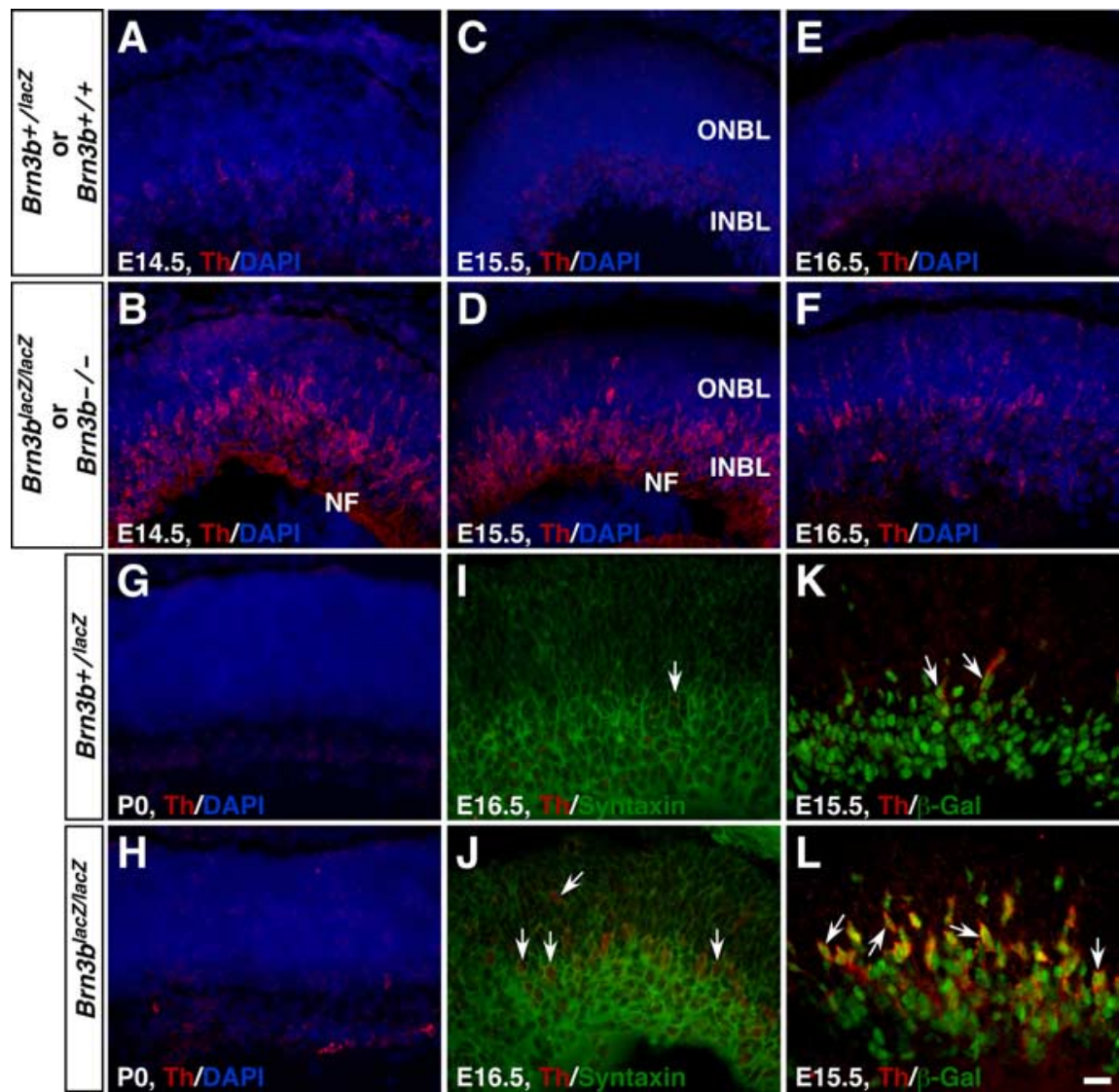

Figure 3. Abnormal generation of dopaminergic amacrine cells in $B r n 3 b$ null retinas. $A-L$, Retinal sections at the indicated

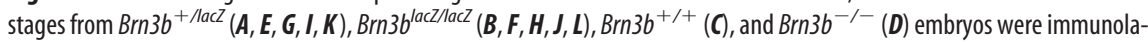
beled with the indicated antibodies. There was a great increase of $\mathrm{TH}$ immunoreactivity in $\mathrm{Brn} 3 \mathrm{~b}$ null retinas that was colocalized with syntaxin and $\beta$-gal (indicated by arrows). Scale bar: (in $L) A-H, 25 \mu \mathrm{m} ; \boldsymbol{I}-\boldsymbol{L}, 16.7 \mu \mathrm{m}$. NF, Nerve fiber. 


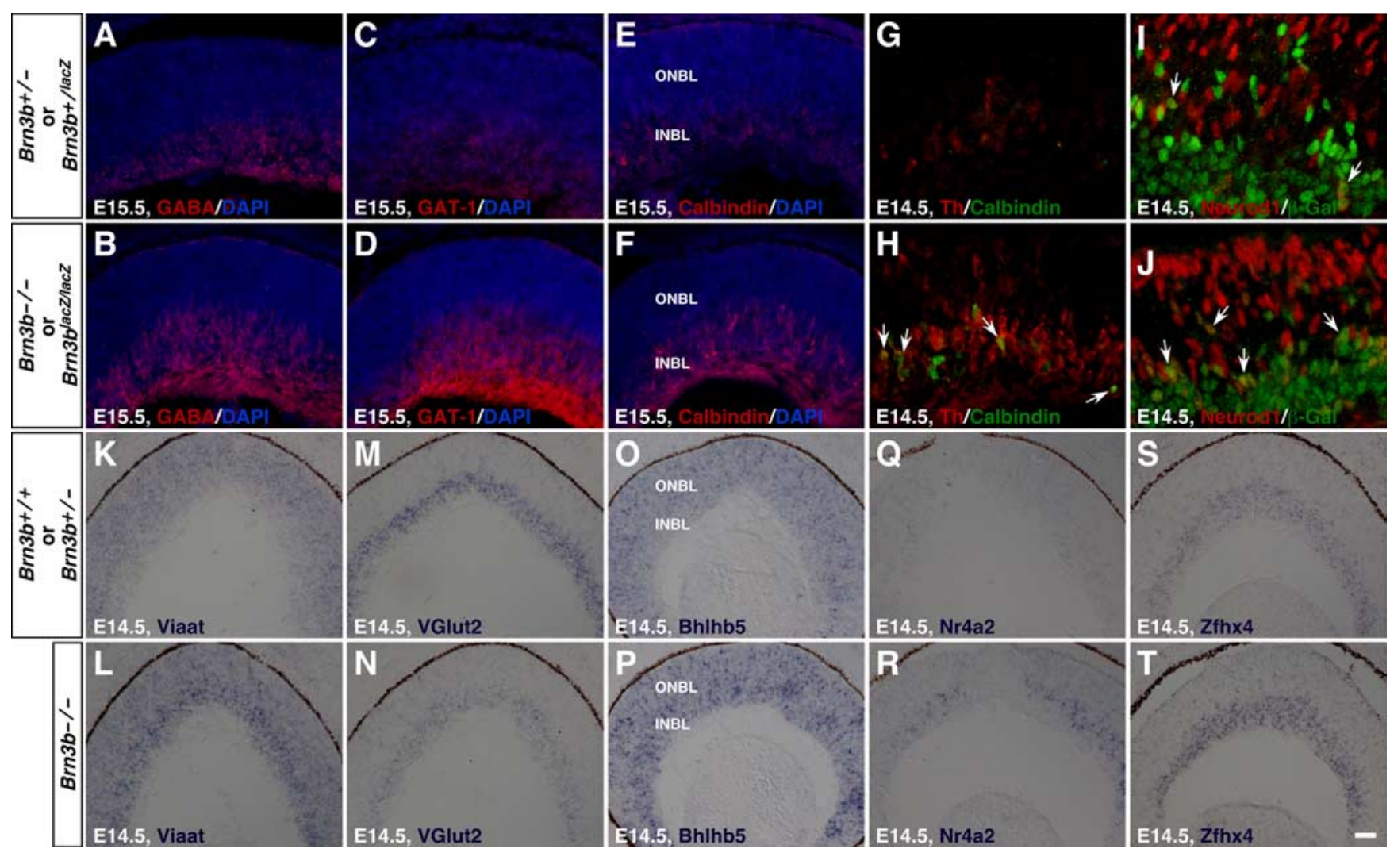

Figure 4. Aberrant differentiation of amacrine cells in Brn3b null retinas. $A-J$, Retinal sections at the indicated stages from $B r n 3 b^{+/-}(\boldsymbol{A}, \boldsymbol{C}, \boldsymbol{E}), B r n 3 b^{-/-}(\boldsymbol{B}, \mathbf{D}, \boldsymbol{F}), B r n 3 b^{+/ l a c z}(\boldsymbol{G}, \boldsymbol{I})$, and

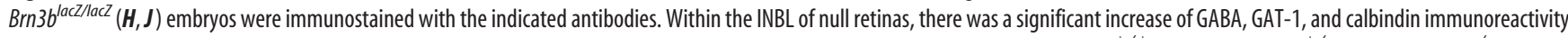
and cells double immunoreactive for TH and calbindin or Neurod 1 and $\beta$-gal (indicated by arrows). $\boldsymbol{K}-\boldsymbol{T}$, E14.5 retinal sections from $B r n 3 b^{+/+}(\boldsymbol{K}, \boldsymbol{M}, \mathbf{Q}, \mathbf{S}), B r n 3 b^{+/-}(\mathbf{O})$, and $B r n 3 b^{-/-}(\boldsymbol{L}, \boldsymbol{N}, \boldsymbol{P}$, $\boldsymbol{R}, \boldsymbol{T}$ ) embryos were in situ hybridized with the indicated RNA probes. Within the INBL of null retinas, there was a significant increase of Viaat, Bhlhb5, Nr4a2, and Zfhx4 expression but a significant decrease of VGlut2 expression. Scale bar: $A-F, 25 \mu \mathrm{m} ; \boldsymbol{G}, \boldsymbol{H}, 16.7 \mu \mathrm{m} ; \boldsymbol{I}, \boldsymbol{J}, 12.5 \mu \mathrm{m} ; \boldsymbol{K}-\boldsymbol{T}, 50 \mu \mathrm{m}$.

in $B r n 3 b$ null retinas, we first examined whether all $\beta$-gal ${ }^{+}$cells would express Brn3b in Brn3b $b^{+/ l a c Z}$ retinas (Gan et al., 1999). At both E12.5 and E14.5, near 100\% (e.g., at E14.5, $99.81 \pm 0.17 \%$, $n=3$ ) of $\beta$-gal-immunoreactive cells were coimmunostained for Brn3b (supplemental Fig. S1, available at www.jneurosci.org as supplemental material), indicating that the knock-in lacZ reporter maintains the cell specificity of Brn3b expression and can serve as a marker for cells that would normally express Brn3b. In $B r n 3 b^{\text {lacZ/lacZ }}$ retinas, nearly all TH-immunoreactive cells were also colabeled for $\beta$-gal (Fig. $3 K, L$ ), suggesting that these cells arise cell autonomously attributable to a switch in fate of precursor cells that would normally express Brn3b and differentiate as RGCs.

To further confirm a possible fate change from RGCs to amacrine cells in Brn3b null retinas, we examined the expression of other amacrine cell markers by immunostaining and RNA in situ hybridization. Compared with control heterozygous retinas, a marked increase was observed in the expression of GABA, GAT-1, calbindin D28K, and Viaat within the INBL of null retinas (Fig. $4 A-F, K, L)$. Additionally, a small number of calbindin ${ }^{+}$ cells were shown to coexpress TH (Fig. 4G,H). These data agree well with the transcript increase of GAT-1, Viaat, and calbindin $\mathrm{D} 28 \mathrm{~K}$ in null retinas revealed by microarray analysis (supplemental Table S1, available at www.jneurosci.org as supplemental material) and suggest that GABAergic amacrine cells abnormally form in early embryonic retinas in the absence of Brn3b. In contrast, the RGC-specific gene VGlut2 (Slc17a6), encoding the vesicular glutamate transporter 2 , displayed greatly reduced expres- sion in null retinas (Fig. 4M,N) (supplemental Table S1, available at www.jneurosci.org as supplemental material).

We next investigated how Brn3b may prevent competent RGC precursors from differentiating into amacrine cells by examining expression of candidate transcription factor genes involved in amacrine cell development. By microarray analysis, in situ hybridization, and qRT-PCR, we were able to show that mRNA transcripts for Bhlhb5, Nr4a2/Nurr1, Neurod1, Math3, $P t f 1 a$, and $Z f h x 4$ all exhibited significant increase in Brn $3 b$ null retinas (Figs. $2 \mathrm{~B}, 4 \mathrm{O}-\mathrm{T}$ ) (supplemental Table S1, available at www.jneurosci.org as supplemental material). These increases were most evident within the INBL (Fig. 4O-T), consistent with the abnormal differentiation of most amacrine cells in this layer of the mutant retina (Figs. 3, 4A-H). Besides the increase of its mRNA, we additionally showed a corresponding increase of Neurod1 protein expression within the INBL of the mutant retina (Fig. 4I,J). Because Neurod1, Math3, and Ptfla have been shown to be required for specifying amacrine cells and Bhlhb5 involved in the differentiation of GABAergic amacrine cells (Inoue et al., 2002; Feng et al., 2006; Fujitani et al., 2006), Brn3b appears to suppress the identity of amacrine cells by repressing genes required for their specification. Although no role has been assigned for the amacrine cell-specific Zfhx4 (Blackshaw et al., 2004), $\mathrm{Nr} 2 \mathrm{a} 4$ is required for specifying dopaminergic neurons in the midbrain (Zetterstrom et al., 1997; Saucedo-Cardenas et al., 1998), suggesting a possibility that Brn3b may inhibit the formation of $\mathrm{TH}^{+}$dopaminergic amacrine cells through its negative regulation of $\mathrm{Nr} 2 a 4$ in the retina. 


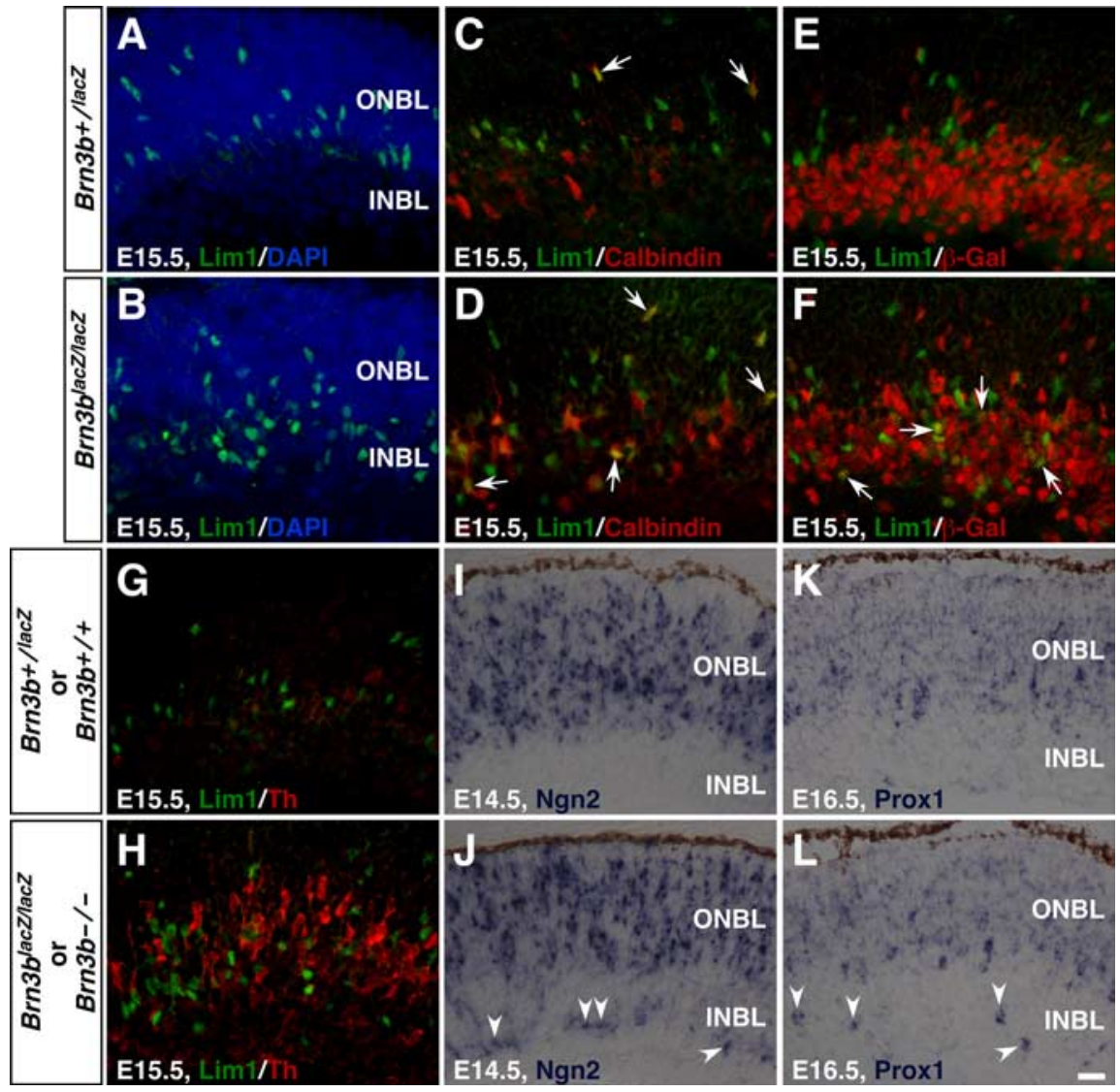

Figure 5. Aberrant differentiation of horizontal cells in Brn3b null retinas. $\boldsymbol{A}-\boldsymbol{H}, \mathrm{E} 15.5$ retinal sections from $B r n 3 b^{+/ l a c z}(\boldsymbol{A}, \boldsymbol{C}$, $\boldsymbol{E}, \boldsymbol{G})$ and $B r n 3 b^{\text {lacZ/lacZ }}(\boldsymbol{B}, \boldsymbol{D}, \boldsymbol{F}, \boldsymbol{H})$ embryos were immunostained with the indicated antibodies. Within the INBL of null retinas, there was a significant increase of Lim1-immunoreactive cells and cells double immunoreactive for Lim1 and calbindin or Lim1 and $\beta$-gal (indicated by arrows), whereas there was no colocalization between $L i m 1$ and TH. $I-L$, Retinal sections at the indicated stages from Brn3b $b^{+/+}(\boldsymbol{I}, \boldsymbol{K})$ and $B r n 3 b^{-/-}(\boldsymbol{J}, \boldsymbol{L})$ embryos were in situ hybridized with Ngn2 or Prox 1 probes. Ngn2 and Prox 1 signals were absent from the INBL of control retinas but appeared in the layer of null retinas (indicated by arrowheads). Scale bar: $A, B, I-L, 25 \mu \mathrm{m} ; C-H, 12.5 \mu \mathrm{m}$.

Abnormal generation of horizontal cells in Brn3b null retinas To assess whether RGC precursors would follow a pathway to horizontal cell differentiation in the absence of Brn3b, we examined by immunostaining in Brn3b null retinas the expression of Lim 1 and calbindin D28K, two horizontal cell markers whose transcripts were shown to increase significantly in microarray and qRT-PCR analyses (Fig. 2) (supplemental Table S1, available at www.jneurosci.org as supplemental material). In E15.5 control wild-type and heterozygous retinas, most Lim1-immunoreactive cells resided within the ONBL; few were present within the INBL (Fig. 5A). In Brn3b null retinas, however, there was a prominent increase of these cells in the INBL $\left(B r n 3 b^{+/-}\right.$: mean \pm SD, $27.4 \pm$ 4.4 cells/optical field, $n=5 ; B r n 3 b^{-/-}: 65.2 \pm 4.4$ cells/optical field, $n=5$ ) (Fig. $5 B$ ). Moreover, double-immunostaining revealed a significant increase of cells immunoreactive for both Lim 1 and the more mature horizontal cell marker calbindin (Fig. $5 C, D)$, suggesting that loss of Brn3b function causes increased horizontal cell differentiation and that the extraneous amacrine and horizontal cells both contribute to the observed increase of calbindin expression in null retinas. In Brn3 $b^{\text {lacZ/lac }}$ retinas, many Lim1-immunoreactive cells could be shown to coexpress $\beta$-gal, whereas these double-immunoreactive cells were absent from $B r n 3 b^{+/ l a c Z}$ retinas (Fig. $5 E, F$ ), suggesting that the extraneous horizontal cells arise cell autonomously from precursor cells that would normally differentiate as RGCs. Conversely, Lim1 was not coexpressed with TH or Brn3a in Brn3b null mutant retinas (Figs. 5G,H, 6G,H), indicating that, in the absence of $B r n 3 b$, the supposed RGC precursors follow independent differentiation pathways to form horizontal, amacrine, or ganglion cells and that these pathways may not be activated simultaneously in a single precursor cell.

Microarray and qRT-PCR analyses revealed in Brn3b null retinas a significant increase of transcripts for Proxl, Ptfla, Lim1, and Ngn2 (Fig. 2) (supplemental Table S1, available at www. jneurosci.org as supplemental material), which are all transcription factor genes involved in horizontal cell development (Liu et al., 2000a; Dyer et al., 2003; Akagi et al., 2004; Fujitani et al., 2006; Poche et al., 2007). Similar to the increase of Lim1 expression within the INBL of $B r n 3 b$ null retinas (Fig. 5A-H), Ngn2 and Prox1 transcripts were also found in this layer in which they were usually absent in the control retinas (Fig. 5I-L). Therefore, Brn3b appears to prevent RGC precursors from differentiating into horizontal cells by repressing expression of transcription factor genes required for their specification and differentiation.

\section{Abnormal generation of RGCs in $\mathrm{Brn} 3 b$ null retinas}

Contrary to previous studies suggesting the normal generation of RGCs in Brn3b null retinas (Gan et al., 1999; Wang et al., 2000), our analyses revealed the production of many amacrine and horizontal cells from the purported RGC precursors in the absence of $B r n 3 b$. This new information prompted us to investigate whether and what RGCs might be generated in the mutant retina. Consistent with a previous observation (Quina et al., 2005), we found by double immunolabeling that the great majority of $\mathrm{Brn} 3 \mathrm{~b}^{+}\left(\beta\right.$-gal $\left.{ }^{+}\right)$cells within the INBL expressed Brn3a in E15.5 $B r n 3 b^{+/ l a c Z}$ retinas (Fig. $6 A$ ). In $B r n 3 b^{\text {lac } Z \text { /lac } Z}$ retinas, a drastically reduced but consistent number of Brn3a-immunoreactive cells were present that coexpressed $\beta$-gal (Fig. $6 B$ ). The Brn $3 \mathrm{a}^{+}$cells did not coexpress TH or Lim 1 (Fig. $6 E-H$ ), thereby exhibiting no properties of amacrine and horizontal cells. They persisted until postnatal and adult stages in null retinas (Fig. 6C,D and data not shown) (Gan et al., 1999). Similarly, an even smaller number of Brn3c-immunoreactive cells were present in embryonic and postnatal Brn3b null retinas that did not coexpress TH or Lim1 (Fig. 6I,J) (Xiang, 1998). Thus, the presumptive RGC precursors in $\mathrm{Brn} 3 \mathrm{~b}$ null retinas produce only a small number of RGCs that express Brn3a and/or Brn3c whose function has been shown to be equivalent to Brn3b (Liu et al., 2000b; Wang et al., 2002; Pan et al., 2005); however, unlike the aberrant amacrine and horizontal cells that die during late embryonic stages, they can survive postnatally.

Dlx1 and Dlx2 are two homeodomain transcription factors that are expressed in RGC precursors and differentiated RGCs and are required for specifying late-born RGCs (de Melo et al., 2003; de Melo et al., 2005). Their transcripts were among the 
most upregulated in Brn3b null retinas as determined by microarray analysis (Fig. 2A) (supplemental Table S1, available at www.jneurosci.org as supplemental material), suggesting a possible misspecification of late-born RGCs in the mutant. We examined this possibility by RNA in situ hybridization. At E14.5, scattered hybridization signals for $D l x 1$ and $D l x 2$ were seen in the ONBL but absent from the INBL of $B r n 3 b^{+/+}$retinas (Fig. $6 K, M$ ), consistent with their protein distribution pattern (de Melo et al., 2003). In Brn3b ${ }^{-/-}$retinas, however, both $D l x 1$ and $D l x 2$ were expressed within the INBL in addition to the overall increase of hybridization signals (Fig. 6L,N), suggesting the generation of extraneous late-born RGCs within the INBL in the absence of Brn3b.

The supernumerary cells that express Dlx1 and Dlx2 in Brn3b null retinas appeared to degenerate as the anomalous amacrine and horizontal cells. First, unlike at E14.5, there was a comparable Dlx2 expression level in the ganglion cell layer between wild-type and null mutant retinas by P7 (Fig. 6O,P). Second, birthdating experiments showed that the great majority of $\beta$-gal ${ }^{+}$cells were born before E16.5 in both $B r n 3 b^{+/ l a c Z}$ and Brn3b $b^{\text {lacZ/lacZ }}$ retinas and that the proportion of $\beta$-gal ${ }^{+}$cells born during late embryonic stages was not higher in Brn3b $b^{\text {lacZ llacZ }}$ retinas (supplemental Fig. S2, available at www.jneurosci.org as supplemental material), implying that abnormal late-born RGCs derived from $\beta$-gal ${ }^{+}$precursors are unlikely to survive beyond birth.

\section{Altered expression of retinogenic factors regulating photoreceptor development}

Aside from RGC, amacrine, and horizontal cells, RGCcompetent precursors have also the potential to generate photoreceptor, in particular, cone cells (Yang et al., 2003; Feng et al., 2006). We thus investigated whether inactivating Brn3b would lead to abnormal photoreceptor cell differentiation as well. Microarray and qRT-PCR analyses revealed in $\mathrm{Brn} 3 \mathrm{~b}^{-/-}$retinas a moderate but significant increase (by 1.2- to 1.4-fold) in mRNA expression of Otx2, Crx , Thrb2, and Prdm1/Blimp1, which all are transcription factor genes involved in photoreceptor cell development (Fig. 2) (Furukawa et al., 1997, 1999; Ng et al., 2001; Nishida et al., 2003; Wilm and Solnica-Krezel, 2005). However, in situ hybridization detected no obvious upregulation in expression of these genes within the mutant INBL (supplemental Fig. $\mathrm{S} 3 A-F$, available at www.jneurosci.org as supplemental material). Consequently, we did not detect by immunolabeling any upregulation of more mature photoreceptor marker proteins recoverin, red/green opsin, or blue opsin in E14.5-E15.5 mutant retinas (data not shown). Similar number of $\mathrm{RXR} \gamma^{+}$cones was produced between control and mutant retinas, and no ectopic cones were seen within the INBL of mutant retinas (supplemental Fig. S3G, $H$, available at www.jneurosci.org as supplemental material). Therefore, loss of Brn3b function results in moderate upregulation in expression of several transcriptional regulators controlling photoreceptor development; however, this upregulation
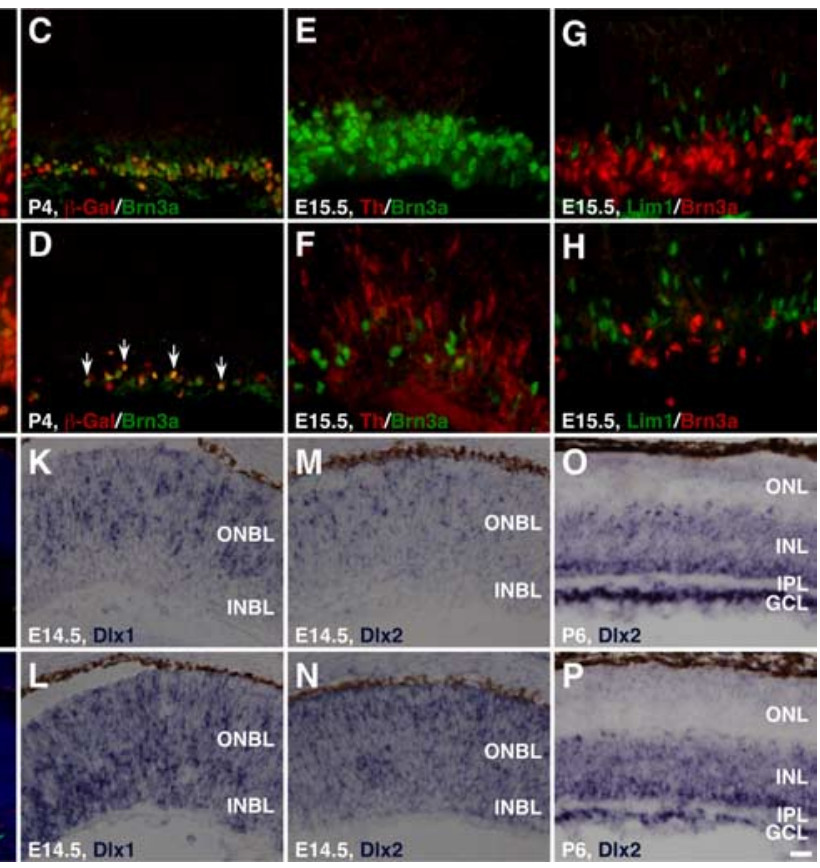

Figure 6. Anomalous generation of $\mathrm{RGCs}$ in $B r n 3 b$ null retinas. $A-J$, Retinal sections at the indicated stages from $B r n 3 b^{+/ l a c z}$ $(\boldsymbol{A}, \boldsymbol{C}, \boldsymbol{E}, \boldsymbol{G}, \boldsymbol{I})$ and $B r n 3 b^{\text {lacZ/lacZ }}(\boldsymbol{B}, \boldsymbol{D}, \boldsymbol{F}, \boldsymbol{H}, \boldsymbol{J})$ mice were immunostained with the indicated antibodies. Within the INBL and ganglion cell layer of null retinas, a small number of Brn3a-immunoreactive cells were seen that coexpressed $\beta$-gal (indicated by ar D/x2 expression was unchanged in the ganglion cell layer of null retinas. GCL, Ganglion cell layer; INL, inner nuclear layer; IPL, r: $C, D, I-P, 25 \mu \mathrm{m} ; \boldsymbol{A}, \boldsymbol{B}, \boldsymbol{E}-\boldsymbol{H}, 16.7 \mu \mathrm{m}$.

does not appear to suffice to cause the presumptive RGC precursors to differentiate as photoreceptors. Among all known transcription factor genes involved in bipolar cell development, although Math3, Ngn2, and Bhlhb5 displayed moderate upregulation (by 1.2 - to 1.9 -fold) in mutant retinas in our microarray dataset (Fig. 2), the others including bipolar cellspecifier genes Chx10 and Mash1 (mammalian achaete-scute homolog 1) did not exhibit any alteration (Burmeister et al., 1996; Tomita et al., 2000; Akagi et al., 2004). Thus, mutant retinas at E14.5-E15.5 did not appear to generate any aberrant bipolar cells because we failed to detect expression of the rod bipolar protein PKC $\alpha$ and the cone bipolar protein recoverin even within the INBL (data not shown). Likewise, there was no abnormal differentiation of Müller cells or upregulation of their specifier genes such as Hes1, Hes5, and Notch1 in Brn3b null retinas (data not shown) (Furukawa et al., 2000; Hojo et al., 2000), most likely manifesting the fact that RGC-competent precursors do not give rise to bipolar or glial cells and that Brn3b ceases to express in precursor cells at the time of bipolar and Müller cell generation.

\section{Altered pattern of cell generation in $B r n 3 b$ null retinas}

Because of different timing of birth of various retinal cell types, the production of supernumerary amacrine, horizontal, and lateborn RGCs in Brn3b null retinas may perturb the normal pattern of early retinal cell generation. To test this possibility, we made use of the $l a c Z$ reporter knocked in the $B r n 3 b$ locus to monitor newly generated retinal cells that were located in the ONBL (supplemental Fig. S4, available at www.jneurosci.org as supplemental material). At E12.5 and E14.5, whereas many newborn $\beta$-gal ${ }^{+}$ cells were similarly observed within the ONBL in the ventral region of $B r n 3 b^{+/ l a c Z}$ and $B r n 3 b^{\text {lacZ/lacZ }}$ retinas (supplemental Fig. 
S4C-F, available at www.jneurosci.org as supplemental material), there was a significant increase of $\beta$-gal ${ }^{+}$cells within the ONBL in the dorsal region of the null retina (supplemental Fig. $\mathrm{S} 4 A, B, G, H$, available at www.jneurosci.org as supplemental material). In E15.5-E17.5 retinas, this increase of $\beta$-gal ${ }^{+}$cells within the ONBL became apparent in the entire null retina compared with the control (supplemental Fig. S4I-L, available at www. jneurosci.org as supplemental material), most likely manifesting the production of more amacrine, horizontal, and late-born RGCs. In agreement with the elevation of newborn $\beta$-gal ${ }^{+}$cells in the dorsal region of mutant retinas during early retinogenesis, many more $\mathrm{Lim} 1^{+}$horizontal cells were formed within the INBL of the dorsal region than of the ventral region in E16.5 Brn3 $b^{\text {lacZ/ }}$ lac $Z$ retinas (supplemental Fig. $S 4 M-P$, available at www. jneurosci.org as supplemental material). Therefore, a fate switch in the presumptive RGC precursors in $\mathrm{Brn} 3 \mathrm{~b}$ null retinas results in an alteration of retinal cell generation pattern, which may reflect the anomalous production of more later-born cell types.

\section{Brn3b acts as a repressor for non-RGC cell differentiation}

The upregulation of non-RGC cells and their associated markers and regulators in Brn3b null retinas implies that Brn3b may have the capacity to suppress development of non-RGC cell types. We tested this possibility by a gain-of-function approach using a replication-incompetent murine retroviral vector that carries a GFP reporter gene (Fig. 7A) (Li et al., 2004b; Mo et al., 2004). Retinal progenitors were infected at $\mathrm{P} 0$ by subretinal injection of Brn3b-GFP or control-GFP viruses, and we analyzed the laminar position and morphology of $\mathrm{GFP}^{+}$cells in infected retinas at P21. In retinas infected with control-GFP viruses, the large majority of $\mathrm{GFP}^{+}$cells differentiated as photoreceptors randomly distributed within the outer nuclear layer (ONL), with $43.3 \%$ of their cell bodies located in the outer half of the ONL and $41.6 \%$ in the inner half of the ONL (Fig. $7 B-D$ ). In retinas infected with Brn3b-GFP viruses, the great majority of $\mathrm{GFP}^{+}$cells also moved into the ONL, but $76.5 \%$ of the cell bodies were observed in the outer half of the ONL and only $12.1 \%$ in the inner half of the ONL (Fig. $7 B-D$ ). Moreover, most of the $\mathrm{GFP}^{+}$cells in the ONL lacked the inner and outer segments typical of photoreceptors seen in control retinas (Fig. $7 B, C$ ). In the inner nuclear layer, the proportion of $\mathrm{GFP}^{+}$cells decreased from $15.8 \%$ in the control to $11.0 \%$ in retinas infected with Brn3b-GFP viruses; there was no difference in the number of $\mathrm{GFP}^{+}$cells distributed in the ganglion cell layer in retinas infected with either control-GFP or Brn3b-GFP viruses (Fig. 7D). Thus, forced Brn3b expression in progenitors dramatically alters the pattern of progeny distributed in different retinal cell layers.

The aberrant distribution of $\mathrm{GFP}^{+}$cells in retinas infected with Brn3b-GFP viruses could be attributable to inappropriate cell differentiation or anomalous cell migration. To distinguish these possibilities, we used a variety of cell-type-specific markers to analyze the types of cells that were differentiated from the virus-infected progenitors. By double immunofluorescence, we found that misexpressed Brn3b appeared to reduce the number of $\mathrm{GFP}^{+}$cells immunoreactive for several cellular markers (Fig. 8). For amacrine cell markers, it reduced the percentage of $\mathrm{GABA}^{+}$cells from 1.82 to $0.84 \%, \mathrm{GLYT}^{+}{ }^{+}$cells from 1.46 to $0.00 \%$, Pax $^{+}$cells from 2.21 to $0.87 \%$, and calbindin ${ }^{+}$cells from 0.57 to $0.04 \%$ (Fig. $8 A-H, Q$ ). As well, it decreased the fraction of recoverin ${ }^{+}$photoreceptor cells from 78.13 to $14.45 \%$, Chx $10^{+}$bipolar cells from 2.58 to $1.24 \%$, and glutamine synthase-positive $\left(\mathrm{GS}^{+}\right.$) Müller cells from 2.29 to $1.42 \%$ (Fig. $8 I-N, Q)$. Most of the $\mathrm{GFP}^{+}$cells $\left(70.5 \%\right.$ of all $\mathrm{GFP}^{+}$cells) lo-
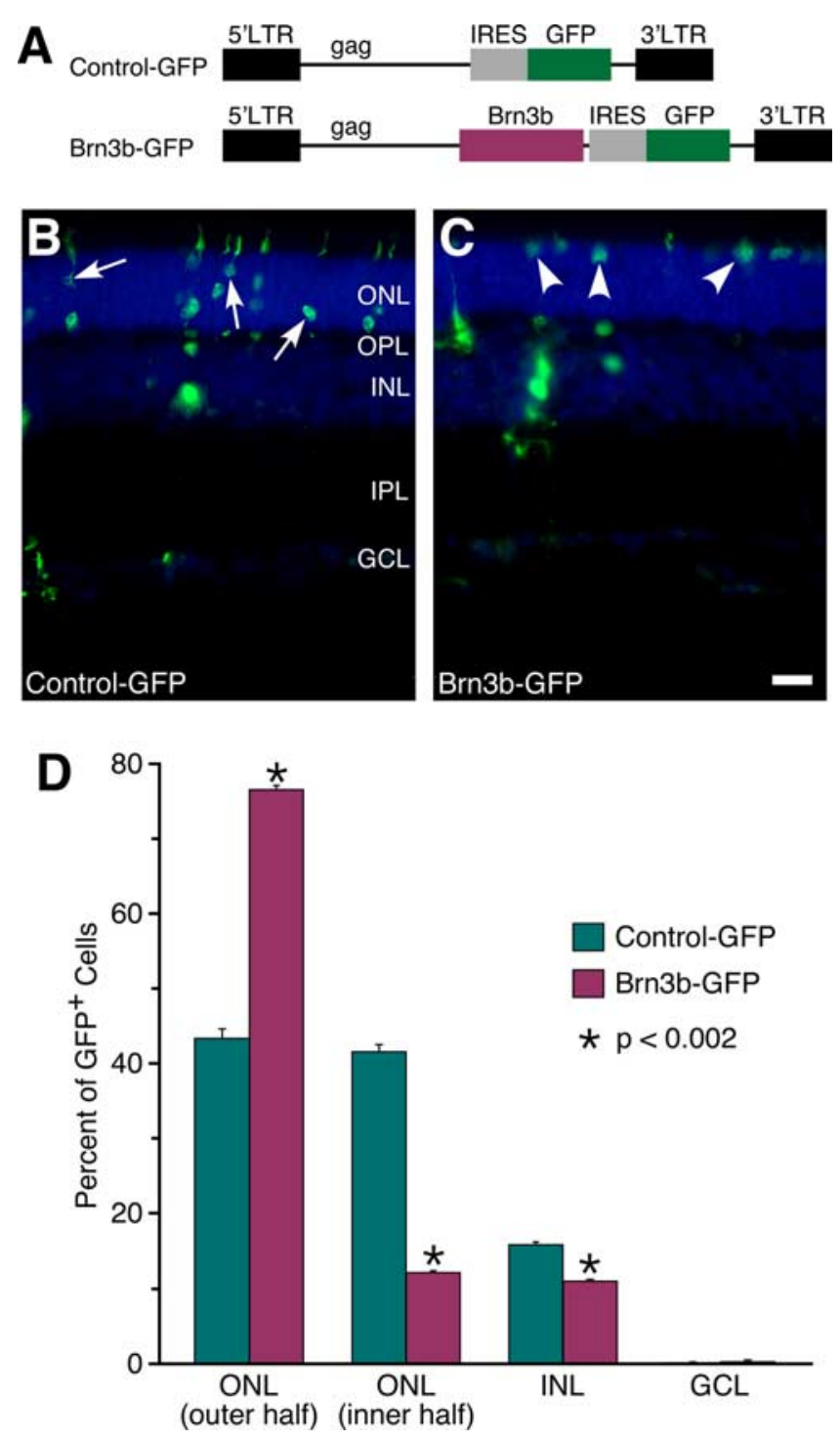

Figure 7. Brn3b misexpressed at $\mathrm{P} 0$ alters the distribution pattern and morphology of retinal cells. $\boldsymbol{A}$, Schematic of control-GFP and Brn3b-GFP retroviral constructs. The internal ribosomal entry site (IRES) allows efficient expression of both Brn3b and GFP. B, C, Virus-transduced GFP ${ }^{+}$ cells were visualized in retinal sections that were weakly counterstained with DAPI. Forced Brn3b expression caused a dramatic increase of cells with large somata situated at the outer edge of the ONL. The arrows indicate photoreceptors $(\boldsymbol{B})$ and arrowheads point to unidentified abnormal cells (C). D, Percentages of virus-transduced cells located in different cellular layers of the retina (means \pm SD). More than $500 \mathrm{GFP}^{+}$cells in three retinas were scored for either control-GFP or Brn3b-GFP virus. GCL, Ganglion cell layer; INL, inner nuclear layer; IPL, inner plexiform layer; LTR, long-term repeat; OPL, outer plexiform layer. Scale bar: $\boldsymbol{B}, \mathbf{C}, 16.7 \mu \mathrm{m}$.

cated within the outer edge of the ONL in retinas infected with Brn3b-GFP viruses were non-immunoreactive for the above tested markers and were additionally negative for the cone cell markers red/green and blue opsins (Fig. 8 and data not shown), suggesting that they are not differentiated retinal cells that are dislocated because of improper migration. Rather, these unidentified cells most likely represent some kind of immature cells whose differentiation is prevented by misexpressed Brn3b.

For horizontal cells and RGCs that are barely produced postnatally, few, if any, $\mathrm{GFP}^{+}$cells became calbindin ${ }^{+}$horizontal cells or Brn3a ${ }^{+}$RGCs when P0 retinas were infected with either control-GFP or Brn3b-GFP viruses (Fig. 8G, H,O-Q). Therefore, to examine the effect of misexpressed Brn3b on these two cell types, we infected retinal explants at E13.5 when progenitor 

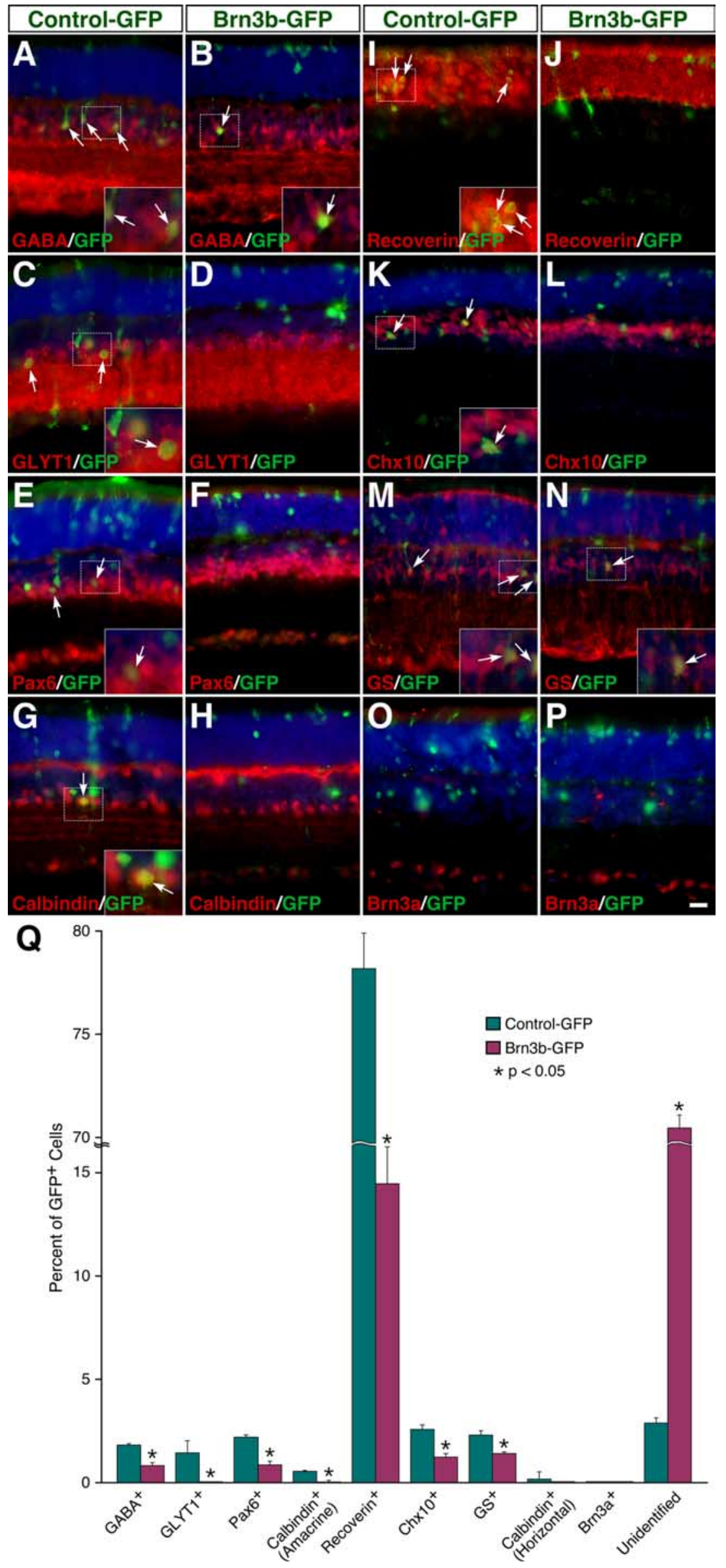

cells are still competent for producing these cells. The infected retinas were harvested after $4.5 \mathrm{~d}$ in culture to analyze RGC and horizontal cells or collected after $12.5 \mathrm{~d}$ in culture for the analysis of other cell types. We found that misexpressed Brn3b increased Brn3a ${ }^{+}$RGCs by approximately ninefold but decreased Lim $1^{+}$horizontal cells by ninefold (supplemental Fig. S5A$D, I$, available at www.jneurosci.org as supplemental material). It also significantly reduced Pax6 $^{+}$amacrine, recoverin ${ }^{+}$ photoreceptor, $\mathrm{Chx} 10^{+}$bipolar, and $\mathrm{GS}^{+}$ Müller cells (supplemental Fig. S5E-I, available at www.jneurosci.org as supplemental material), similar to its effect in retinas infected at $\mathrm{P} 0$ (Fig. 8). In explants infected with either control-GFP or Brn3b-GFP viruses, most of the GFP-positive cells in the ONL were negative for rhodopsin, red/green opsin, or blue opsin, just like recoverin (supplemental Fig. S5E,F,I, available at www.jneurosci.org as supplemental material), indicating them as undifferentiated/partially differentiated immature cells. Together, these overexpression data have demonstrated that Brn3b has the ability not only to promote an RGC fate but also to suppress the differentiation of several non-RGC cell types, including amacrine and horizontal cells, in agreement with the finding in $\mathrm{Brn} 3 \mathrm{~b}$ null retinas.

\section{Discussion \\ $B r n 3 b$ acts as a specifier gene for RGC development}

Brn3b is thought to be required only for differentiation of RGCs but dispensable for driving retinal precursors toward an RGC fate (Gan et al., 1999; Mu and Klein, 2004). Therefore, a hypothetical TF gene has been proposed to serve as an RGC specifier gene (Mu and Klein, 2004). However, our studies have provided several lines of evidence

Figure 8. Effect of $\mathrm{Brn} 3 \mathrm{~b}$ misexpressed at $\mathrm{PO}$ on the formation of different retinal cell types. $\boldsymbol{A}-\boldsymbol{P}$, Sections from retinas infected with control-GFP or Brn3b-GFP viruses were double immunostained with an anti-GFP antibody and antibodies against GABA, GLYT1, Pax6, calbindin, recoverin, Chx10, GS, or Brn3a. Sections in $\boldsymbol{A}-\boldsymbol{H}$ and $\boldsymbol{K} \boldsymbol{- P}$ were weakly counterstained with DAPI. Forced Brn3b expression in P0 retinas resulted in a significant decrease of amacrine cells immunoreactive for GABA, GLYT1, Pax6, and calbindin ( $\boldsymbol{A}-\boldsymbol{H})$, photoreceptor cells immunoreactive for recoverin $(I, J)$, bipolar cells immunoreactive for Chx10 $(\boldsymbol{K}, \boldsymbol{L})$, and Müller cells immunoreactive for GS $(M, N)$, whereas it had no effect on $\mathrm{RGCS}$ immunoreactive for $\operatorname{Brn3a}(\mathbf{O}, \mathbf{P})$. Arrows point to representative colocalized cells, and insets show them at a higher magnification. Q, Quantitation of virus-transduced retinal cells that became immunoreactive for a series of cell-type-specific markers. Each histogram represents the mean $\pm S D$ for three retinas. More than 400 $\mathrm{GFP}^{+}$cells were scored in each retina. The unidentified cells were those that were located at the outer edge of the ONL but negative for recoverin. Scale bar: $\boldsymbol{A}-\boldsymbol{P}, 16.7 \mu \mathrm{m}$. 


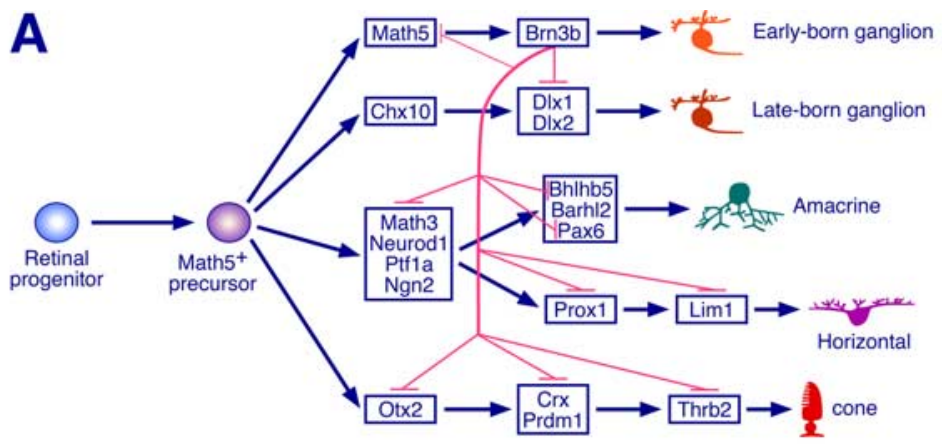

B

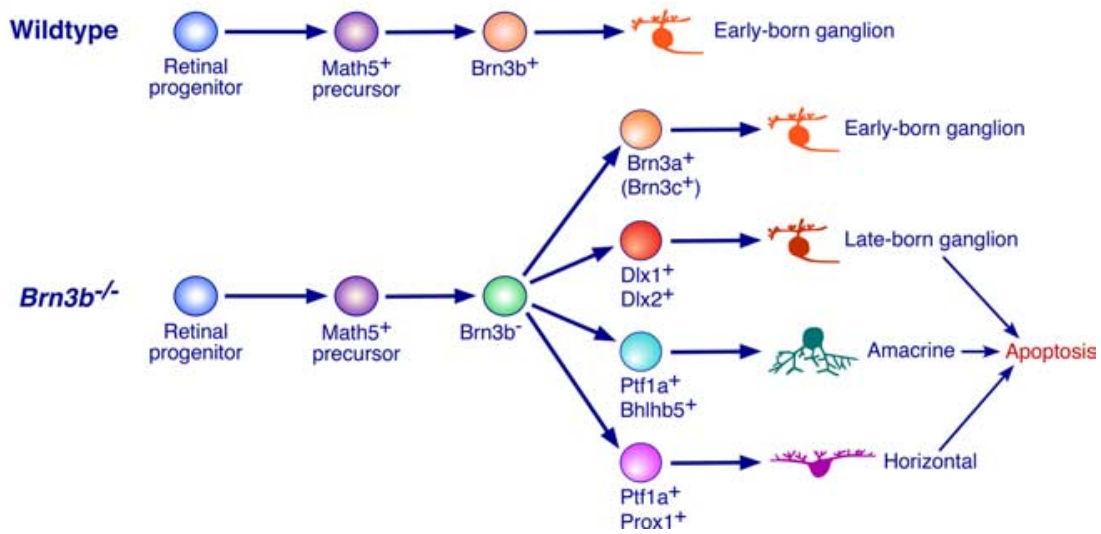

Figure 9. Schematics illustrating the safeguard mechanism by which Brn3b specifies early-born RGCs. A, RGC-competent Math ${ }^{+}$precursors are able to generate early-born and late-born RGCs and amacrine, horizontal, and cone cells. When Brn3b is expressed in such a multipotential precursor, it commits it to an early-born RGC fate but prevents it from following other differentiation pathways by repressing the expression of a network of retinogenic transcription factor genes involved in fate commitment and differentiation of late-born RGC, amacrine, horizontal, and cone cells. $\boldsymbol{B}$, When expressed in RGC-competent precursors, Brn3b specifies early-born RGCs and promotes their differentiation in wild-type retinas. In the mutant, the safeguard mechanism is compromised and the precursors that would normally express Brn3b switch their fates to aberrantly produce late-born RGC, amacrine, and horizontal cells that would quickly degenerate by apoptosis. In addition, a small portion of earlyborn RGCs are produced because of functional compensation by Brn3a and Brn3c.

to show this not to be the case and to identify Brn3b itself as an RGC specifier gene: (1) whereas inactivating a gene involved only in differentiation would not result in a cell fate change, loss of Brn3b function clearly causes most of the presumptive RGC precursors to switch to amacrine or horizontal cell fates as revealed by a variety of molecular markers; (2) there appears to be a shift in the production of RGCs from early-born to late-born types in $B r n 3 b$ null retinas as evidenced by the increase of $D l x 1$ and $D l \times 2$ expression within the INBL; (3) consistent with a fate change in Brn3b null retinas, only a small number of early-born RGCs are generated as marked by Brn3a or Brn3c; (4) cell generation pattern is altered in early Brn $3 b$ null retinas in a manner that is consistent with the production of more later-born cell types; (5) misexpressed Brn3b is capable of repressing non-RGC differentiation as well as promoting RGC formation; and (6) microarray analysis has identified in Brn3b null retinas not only a large set of downregulated genes crucial for RGC function but also a large number of upregulated genes involved in non-RGC development.

The earlier conclusion that Brn3b must be required only for RGC differentiation primarily comes from the characterization of $B r n 3 b^{\text {lacZ-ki/lacZ-ki }}$ retinas in which a normal number of $\beta$-gal ${ }^{+}$ cells was produced that migrated into the INBL by E14.5 (Gan et al., 1999). All of these $\beta$-gal ${ }^{+}$cells were assumed to be RGCs despite the fact that they were not confirmed as such using molecular markers. We now show that many of the $\beta$-gal ${ }^{+}$cells in
Brn3b null retinas coexpress TH or Lim1 but not Brn3a or Brn3c (Figs. 3, 5, 6), thereby indicating them as amacrine and horizontal cells rather than RGCs. Moreover, TH, Lim1, and Brn3a/Brn3c are mutually exclusive in their expression in $\mathrm{Brn} 3 \mathrm{~b}$ null retinas (Figs. 5, 6), suggesting that the $\beta$-gal ${ }^{+}$cells in Brn3b mutants follow separate differentiation pathways and do not develop as hybrid cells as exemplified by the hybrid photoreceptors present in $\mathrm{Nr} 2 e 3$ null retinas (Chen et al., 2005; Corbo and Cepko, 2005). The cells within the INBL of $B r n 3 b$ null retinas were found to extend shorter, microtubule-rich and nonfasciculated neurites characteristic of dendrites rather than axons (Gan et al., 1999; Wang et al., 2000). This phenomenon has been explained as a change of RGC cell polarity but more likely may reflect a switch from RGCs to dendrite-bearing amacrine and horizontal cells. In fact, ultrastructural analysis reveals that all neurites that do enter the optical nerve in Brn3b null mice, presumably from the residual RGCs, are characteristic of axons, whereas the aberrant neurites stay only in the nerve fiber layer (Wang et al., 2000). It has also been suggested that the presumptive RGCs in $B r n 3 b$ null retinas die because of abnormal axon formation and projection (Gan et al., 1999; Wang et al., 2000). Our data, however, implicate a cause of improper cell specification and differentiation and probably a lack of suitable microenvironmental cues as well.

Our data and others together suggest that Brn3b is crucially required for fate commitment as well as differentiation of RGCs. The small number of RGCs that express Brn3a/Brn3c in Brn3b null retinas appear to differentiate and survive, but they project axons with both intraocular and extraocular pathfinding defects along the visual pathway (Erkman et al., 2000). Notably, when Brn3a is knocked in the Brn3b locus, all phenotypes associated with Brn3b inactivation are completely rescued (Pan et al., 2005). As well, Brn3c displays a functional redundancy with Brn3b (Wang et al., 2002). Therefore, Brn3a and perhaps Brn3c have the ability to fully compensate for Brn3b function when properly expressed. Then why do the residual RGCs that do express Brn3a/Brn3c still exhibit axon pathfinding defects in Brn3b null retinas? We speculate that the differentiation events leading to axon growth and pathfinding occur early and depend on Brn3b function. Brn3a and Brn3c are expressed in RGCs 2 d later than Brn3b, and thus it may be too late for them to perform this early function (Xiang, 1998), whereas a knock-in ensures Brn3a to be expressed in a spatiotemporal pattern precisely as Brn3b (Pan et al., 2005).

\section{Brn3b specifies the RGC fate from multipotential precursors not only by promoting RGC differentiation but by suppressing non-RGC differentiation programs}

Our loss-of-function and gain-of-function data together suggest that Brn3b is capable of exerting a negative influence on the differentiation of all non-RGC Cells. This influence appears to be so 
strong that, when Brn3b is deleted in mice, the precursors that would normally give rise to RGCs actually change their fate to differentiate as amacrine or horizontal cells. This fate change is direct and cellautonomous because the superfluous amacrine and horizontal cells are positive for $\beta$-gal in $B r n 3 b^{\text {lac } Z / l a c Z}$ retinas. Consistent with a cell fate switch, several key TF genes involved in the determination and differentiation of amacrine and horizontal cells are significantly upregulated in Brn3b null retinas. These include Math3, Neurod1, Ngn2, Ptf1a, Bhlhb5, Pax6, Prox1, and Lim1.

During retinogenesis, RGC-competent precursors as defined by Math5 expression are able to generate cone cells in addition to RGC, amacrine, and horizontal cells (Yang et al., 2003; Feng et al., 2006). So it is expected that Brn3b would also inhibit cone cell differentiation. Indeed, there is a moderate upregulation of several photoreceptor regulator genes, including Otx2, Crx, Thrb2, and Prdm1/Blimp1, in $B r n 3 b$ null retinas. Nevertheless, this negative control of photoreceptor regulators appears to be so weak that its release alone is insufficient to convert RGCs into cones in the absence of Brn3b. Targeted Math5 deletion leads to increased cones so Math5 normally represses cone differentiation (Brown et al., 2001). Conceivably, Brn3b may cooperate with Math5 to ensure complete suppression of the cone differentiation program in RGC precursors.

Our gain-of-function studies demonstrate the ability of Brn3b to suppress amacrine, horizontal, and photoreceptor cell differentiation, in agreement with the result derived from Brn3b null retinas. Most bipolar and Müller cells are born postnatally during mouse retinogenesis, and overexpressed Brn3b has the ability to inhibit their differentiation as well despite the fact that removing endogenous Brn $3 b$ does not appear to have a detectable effect on their formation. We speculate that, because RGC-competent precursors do not give rise to bipolar or Müller cells (Yang et al., 2003; Feng et al., 2006), it may be inconsequential if endogenous Brn3b exerts an inhibitory effect on these two cell types. When Brn3b is overexpressed, however, persistent Brn3b expression may turn this inconsequential inhibition into a strong one. It is indeed possible that Brn3b may normally be involved in suppressing bipolar and Müller cell differentiation for the expression of bipolar cell-regulator genes Math3, Ngn2, and Bhlhb5 is significantly upregulated in Brn3b null retinas (Tomita et al., 2000; Akagi et al., 2004; Feng et al., 2006). In postnatal retinas, the sweeping inhibitory effect of Brn3b on all nonRGCs appeared to leave $\sim 70 \%$ of Brn3b-overexpressing cells inappropriately differentiated because they did not express any known cell type markers and stayed at the outer edge of the retina (Figs. 7, 8). They were probably in a confused state, apparently prevented by Brn $3 \mathrm{~b}$ from forming non-RGC cells but meanwhile unable to differentiate as RGCs because postnatal precursors are incompetent for RGC generation.

In summary, our data indicate that Brn3b has a previously unrecognized role, i.e., it acts not only as a differentiation gene but more importantly as a specifier gene in early RGC development. Brn3b appears to facilitate an RGC fate by promoting RGC differentiation as well as suppressing non-RGC fates. RGCcompetent Math5 ${ }^{+}$precursors are now known to be capable of producing Brn3b-dependent early-born RGC, late-born RGC, amacrine, horizontal, and cone cells (Fig. 9A) (Yang et al., 2003; Feng et al., 2006). Thus, to select the early-born RGC fate from the multiple fates available for an RGC-competent precursor, it is conceivable that the commitment factor must suppress nonRGC and late-born RGC fates. We propose that, while promoting the differentiation of early-born RGCs, Brn3b may actively suppress the differentiation of late-born RGC, amacrine, horizontal, and cone cells by repressing a network of TF genes involved in their development (Fig. 9A). Such a comprehensive negative reg- ulatory program may serve as a safeguard mechanism to ensure the differentiation of all Brn3b-expressing precursors as earlyborn RGCs. In the absence of Brn3b, this safeguard mechanism is unleashed, cell fate changes occur, and the supposed RGC precursors now generate amacrine, horizontal, late-born RGC, and early-born RGC cells (Fig. 9B). They do not abnormally produce cones perhaps because another safeguard mechanism provided by other factors such as Math5 is still in place in Brn3b null retinas. Thus, a systematic analysis of the gene networks that other retinogenic factors control is entailed to fully understand the intricate safeguard mechanism underlying the coordinated specification and differentiation of all retinal cell types from multipotent progenitors.

\section{References}

Akagi T, Inoue T, Miyoshi G, Bessho Y, Takahashi M, Lee JE, Guillemot F, Kageyama R (2004) Requirement of multiple basic helix-loop-helix genes for retinal neuronal subtype specification. J Biol Chem 279:28492-28498.

Blackshaw S, Harpavat S, Trimarchi J, Cai L, Huang H, Kuo WP, Weber G, Lee K, Fraioli RE, Cho SH, Yung R, Asch E, Ohno-Machado L, Wong WH, Cepko CL (2004) Genomic analysis of mouse retinal development. PLoS Biol 2:E247.

Brown NL, Patel S, Brzezinski J, Glaser T (2001) Math5 is required for retinal ganglion cell and optic nerve formation. Development 128:2497-2508.

Burmeister M, Novak J, Liang MY, Basu S, Ploder L, Hawes NL, Vidgen D, Hoover F, Goldman D, Kalnins VI, Roderick TH, Taylor BA, Hankin MH, McInnes RR (1996) Ocular retardation mouse caused by Chx10 homeobox null allele: impaired retinal progenitor proliferation and bipolar cell differentiation. Nat Genet 12:376-384.

Chen J, Rattner A, Nathans J (2005) The rod photoreceptor-specific nuclear receptor $\mathrm{Nr} 2 \mathrm{e} 3$ represses transcription of multiple cone-specific genes. J Neurosci 25:118-129.

Chen S, Wang QL, Nie Z, Sun H, Lennon G, Copeland NG, Gilbert DJ, Jenkins NA, Zack DJ (1997) Crx, a novel Otx-like paired-homeodomain protein, binds to and transactivates photoreceptor cell-specific genes. Neuron 19:1017-1030.

Cheng L, Arata A, Mizuguchi R, Qian Y, Karunaratne A, Gray PA, Arata S, Shirasawa S, Bouchard M, Luo P, Chen CL, Busslinger M, Goulding M, Onimaru H, Ma Q (2004) Tlx3 and Tlx1 are post-mitotic selector genes determining glutamatergic over GABAergic cell fates. Nat Neurosci 7:510-517.

Corbo JC, Cepko CL (2005) A hybrid photoreceptor expressing both rod and cone genes in a mouse model of enhanced S-cone syndrome. PLoS Genet 1:e11.

de Melo J, Qiu X, Du G, Cristante L, Eisenstat DD (2003) Dlx1, Dlx2, Pax6, Brn3b, and Chx10 homeobox gene expression defines the retinal ganglion and inner nuclear layers of the developing and adult mouse retina. J Comp Neurol 461:187-204.

de Melo J, Du G, Fonseca M, Gillespie LA, Turk WJ, Rubenstein JL, Eisenstat DD (2005) Dlx1 and Dlx2 function is necessary for terminal differentiation and survival of late-born retinal ganglion cells in the developing mouse retina. Development 132:311-322.

Dennis Jr G, Sherman BT, Hosack DA, Yang J, Gao W, Lane HC, Lempicki RA (2003) DAVID: database for annotation, visualization, and integrated discovery. Genome Biol 4:P3.

Dizhoor AM, Ray S, Kumar S, Niemi G, Spencer M, Brolley D, Walsh KA, Philipov PP, Hurley JB, Stryer L (1991) Recoverin: a calcium sensitive activator of retinal rod guanylate cyclase. Science 251:915-918.

Dyer MA, Cepko CL (2001) Regulating proliferation during retinal development. Nat Rev Neurosci 2:333-342.

Dyer MA, Livesey FJ, Cepko CL, Oliver G (2003) Proxl function controls progenitor cell proliferation and horizontal cell genesis in the mammalian retina. Nat Genet 34:53-58.

Erkman L, McEvilly RJ, Luo L, Ryan AK, Hooshmand F, O'Connell SM, Keithley EM, Rapaport DH, Ryan AF, Rosenfeld MG (1996) Role of transcription factors Brn-3.1 and Brn-3.2 in auditory and visual system development. Nature 381:603-606.

Erkman L, Yates PA, McLaughlin T, McEvilly RJ, Whisenhunt T, O'Connell SM, Krones AI, Kirby MA, Rapaport DH, Bermingham JR, O'Leary DD, Rosenfeld MG (2000) A POU domain transcription factor-dependent 
program regulates axon pathfinding in the vertebrate visual system. Neuron 28:779-792.

Feng L, Xie X, Joshi PS, Yang Z, Shibasaki K, Chow RL, Gan L (2006) Requirement for Bhlhb5 in the specification of amacrine and cone bipolar subtypes in mouse retina. Development 133:4815-4825.

Fujitani Y, Fujitani S, Luo H, Qiu F, Burlison J, Long Q, Kawaguchi Y, Edlund H, Macdonald RJ, Furukawa T, Fujikado T, Magnuson MA, Xiang M, Wright CV (2006) Ptfla determines horizontal and amacrine cell fates during mouse retinal development. Development 133:4439-4450.

Furukawa T, Morrow EM, Cepko CL (1997) Crx , a novel otx-like homeobox gene, shows photoreceptor-specific expression and regulates photoreceptor differentiation. Cell 91:531-541.

Furukawa T, Morrow EM, Li T, Davis FC, Cepko CL (1999) Retinopathy and attenuated circadian entrainment in Crx-deficient mice. Nat Genet 23:466-470.

Furukawa T, Mukherjee S, Bao ZZ, Morrow EM, Cepko CL (2000) rax, Hes1, and notch 1 promote the formation of Müller glia by postnatal retinal progenitor cells. Neuron 26:383-394.

Gan L, Xiang M, Zhou L, Wagner DS, Klein WH, Nathans J (1996) POU domain factor Brn-3b is required for the development of a large set of retinal ganglion cells. Proc Natl Acad Sci USA 93:3920-3925.

Gan L, Wang SW, Huang Z, Klein WH (1999) POU domain factor Brn-3b is essential for retinal ganglion cell differentiation and survival but not for initial cell fate specification. Dev Biol 210:469-480.

Gupta N, Yucel YH (2007) Glaucoma as a neurodegenerative disease. Curr Opin Ophthalmol 18:110-114.

Harris WA (1997) Cellular diversification in the vertebrate retina. Curr Opin Genet Dev 7:651-658.

Harvey AR, Hu Y, Leaver SG, Mellough CB, Park K, Verhaagen J, Plant GW, Cui Q (2006) Gene therapy and transplantation in CNS repair: the visual system. Prog Retin Eye Res 25:449-489.

Hojo M, Ohtsuka T, Hashimoto N, Gradwohl G, Guillemot F, Kageyama R (2000) Glial cell fate specification modulated by the bHLH gene Hes5 in mouse retina. Development 127:2515-2522.

Inoue T, Hojo M, Bessho Y, Tano Y, Lee JE, Kageyama R (2002) Math3 and NeuroD regulate amacrine cell fate specification in the retina. Development 129:831-842.

Kanekar S, Perron M, Dorsky R, Harris WA, Jan LY, Jan YN, Vetter ML (1997) Xath5 participates in a network of bHLH genes in the developing Xenopus retina. Neuron 19:981-994.

Kay JN, Finger-Baier KC, Roeser T, Staub W, Baier H (2001) Retinal ganglion cell genesis requires lakritz, a zebrafish atonal homolog. Neuron 30:725-736.

Kim J, Wu HH, Lander AD, Lyons KM, Matzuk MM, Calof AL (2005) GDF11 controls the timing of progenitor cell competence in developing retina. Science 308:1927-1930.

Le TT, Wroblewski E, Patel S, Riesenberg AN, Brown NL (2006) Math5 is required for both early retinal neuron differentiation and cell cycle progression. Dev Biol 295:764-778.

Li C, Wong WH (2003) DNA-Chip Analyzer (dChip). In: The analysis of gene expression data: methods and software (Parmigiani G, Garrett ES, Irizarry R, Zeger SL, eds), pp 120-141. New York: Springer.

Li S, Qiu F, Xu A, Price SM, Xiang M (2004a) Barhll regulates migration and survival of cerebellar granule cells by controlling expression of the neurotrophin-3 gene. J Neurosci 24:3104-3114.

Li S, Mo Z, Yang X, Price SM, Shen MM, Xiang M (2004b) Foxn4 controls the genesis of amacrine and horizontal cells by retinal progenitors. Neuron 43:795-807.

Li S, Misra K, Matise MP, Xiang M (2005) Foxn4 acts synergistically with Mash1 to specify subtype identity of V2 interneurons in the spinal cord. Proc Natl Acad Sci USA 102:10688-10693.

Liu W, Wang JH, Xiang M (2000a) Specific expression of the LIM/homeodomain protein Lim-1 in horizontal cells during retinogenesis. Dev Dyn 217:320-325.

Liu W, Khare SL, Liang X, Peters MA, Liu X, Cepko CL, Xiang M (2000b) All $\mathrm{Brn} 3$ genes can promote retinal ganglion cell differentiation in the chick. Development 127:3237-3247.

Liu W, Mo Z, Xiang M (2001) The Ath5 proneural genes function upstream of Brn3 POU domain transcription factor genes to promote retinal ganglion cell development. Proc Natl Acad Sci USA 98:1649-1654.

Livesey FJ, Cepko CL (2001) Vertebrate neural cell-fate determination: lessons from the retina. Nat Rev Neurosci 2:109-118.
Ma W, Yan RT, Xie W, Wang SZ (2004) A role of ath5 in inducing neuroD and the photoreceptor pathway. J Neurosci 24:7150-7158.

Mao CA, Kiyama T, Pan P, Furuta Y, Hadjantonakis AK, Klein WH (2008) Eomesodermin, a target gene of Pou4f2, is required for retinal ganglion cell and optic nerve development in the mouse. Development 135:271-280.

Mo Z, Li S, Yang X, Xiang M (2004) Role of the Barhl2 homeobox gene in the specification of glycinergic amacrine cells. Development 131:1607-1618.

$\mathrm{Mu}$ X, Klein WH (2004) A gene regulatory hierarchy for retinal ganglion cell specification and differentiation. Semin Cell Dev Biol 15:115-123.

Mu X, Beremand PD, Zhao S, Pershad R, Sun H, Scarpa A, Liang S, Thomas TL, Klein WH (2004) Discrete gene sets depend on POU domain transcription factor Brn3b/Brn-3.2/POU4f2 for their expression in the mouse embryonic retina. Development 131:1197-1210.

Mu X, Fu X, Sun H, Beremand PD, Thomas TL, Klein WH (2005) A gene network downstream of transcription factor Math5 regulates retinal progenitor cell competence and ganglion cell fate. Dev Biol 280:467-481.

Ng L, Hurley JB, Dierks B, Srinivas M, Salto C, Vennstrom B, Reh TA, Forrest D (2001) A thyroid hormone receptor that is required for the development of green cone photoreceptors. Nat Genet 27:94-98.

Nishida A, Furukawa A, Koike C, Tano Y, Aizawa S, Matsuo I, Furukawa T (2003) Otx2 homeobox gene controls retinal photoreceptor cell fate and pineal gland development. Nat Neurosci 6:1255-1263.

Pan L, Yang Z, Feng L, Gan L (2005) Functional equivalence of Brn3 POUdomain transcription factors in mouse retinal neurogenesis. Development 132:703-712.

Pfaffl MW (2001) A new mathematical model for relative quantification in real-time RT-PCR. Nucleic Acids Res 29:e45.

Poche RA, Kwan KM, Raven MA, Furuta Y, Reese BE, Behringer RR (2007) Lim1 is essential for the correct laminar positioning of retinal horizontal cells. J Neurosci 27:14099-14107.

Quina LA, Pak W, Lanier J, Banwait P, Gratwick K, Liu Y, Velasquez T, O’Leary DD, Goulding M, Turner EE (2005) Brn3a-expressing retinal ganglion cells project specifically to thalamocortical and collicular visual pathways. J Neurosci 25:11595-11604.

Saucedo-Cardenas O, Quintana-Hau JD, Le WD, Smidt MP, Cox JJ, De Mayo F, Burbach JP, Conneely OM (1998) Nurr1 is essential for the induction of the dopaminergic phenotype and the survival of ventral mesencephalic late dopaminergic precursor neurons. Proc Natl Acad Sci USA 95:4013-4018.

Tomita K, Moriyoshi K, Nakanishi S, Guillemot F, Kageyama R (2000) Mammalian achaete-scute and atonal homologs regulate neuronal versus glial fate determination in the central nervous system. EMBO J 19:5460-5472.

Wagner KD, Wagner N, Vidal VP, Schley G, Wilhelm D, Schedl A, Englert C, Scholz H (2002) The Wilms' tumor gene Wt1 is required for normal development of the retina. EMBO J 21:1398-1405.

Wang SW, Gan L, Martin SE, Klein WH (2000) Abnormal polarization and axon outgrowth in retinal ganglion cells lacking the POU-domain transcription factor Brn-3b. Mol Cell Neurosci 16:141-156.

Wang SW, Kim BS, Ding K, Wang H, Sun D, Johnson RL, Klein WH, Gan L (2001) Requirement for math5 in the development of retinal ganglion cells. Genes Dev 15:24-29.

Wang SW, Mu X, Bowers WJ, Kim DS, Plas DJ, Crair MC, Federoff HJ, Gan L, Klein WH (2002) Brn3b/Brn3c double knockout mice reveal an unsuspected role for Brn3c in retinal ganglion cell axon outgrowth. Development 129:467-477.

Wilm TP, Solnica-Krezel L (2005) Essential roles of a zebrafish prdm1/ blimp1 homolog in embryo patterning and organogenesis. Development 132:393-404.

Xiang M (1998) Requirement for Brn-3b in early differentiation of postmitotic retinal ganglion cell precursors. Dev Biol 197:155-169.

Xiang M, Zhou L, Peng YW, Eddy RL, Shows TB, Nathans J (1993) Brn-3b: a POU domain gene expressed in a subset of retinal ganglion cells. Neuron 11:689-701.

Xiang M, Zhou L, Macke JP, Yoshioka T, Hendry SH, Eddy RL, Shows TB, Nathans J (1995) The Brn-3 family of POU-domain factors: primary structure, binding specificity, and expression in subsets of retinal ganglion cells and somatosensory neurons. J Neurosci 15:4762-4785.

Yang Z, Ding K, Pan L, Deng M, Gan L (2003) Math5 determines the competence state of retinal ganglion cell progenitors. Dev Biol 264:240-254.

Zetterstrom RH, Solomin L, Jansson L, Hoffer BJ, Olson L, Perlmann T (1997) Dopamine neuron agenesis in Nurr1-deficient mice. Science 276: $248-250$. 